\title{
A.4.
}

-5m

2.

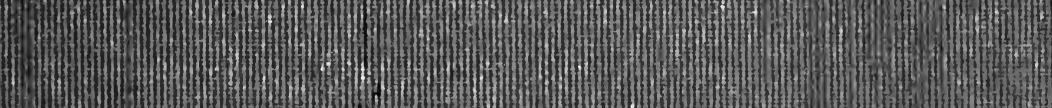




$$
\text { • }
$$


Prumber

ec

Qun

ए厂



妥

坚

$\sum$ 드

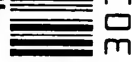

金蓑

एᄑ

를

” 


$$
\text { , }
$$




\section{THE CONQUEST OF DISEASE}

\section{THROUGH}

ANIMAL EXPERIMENTATION 



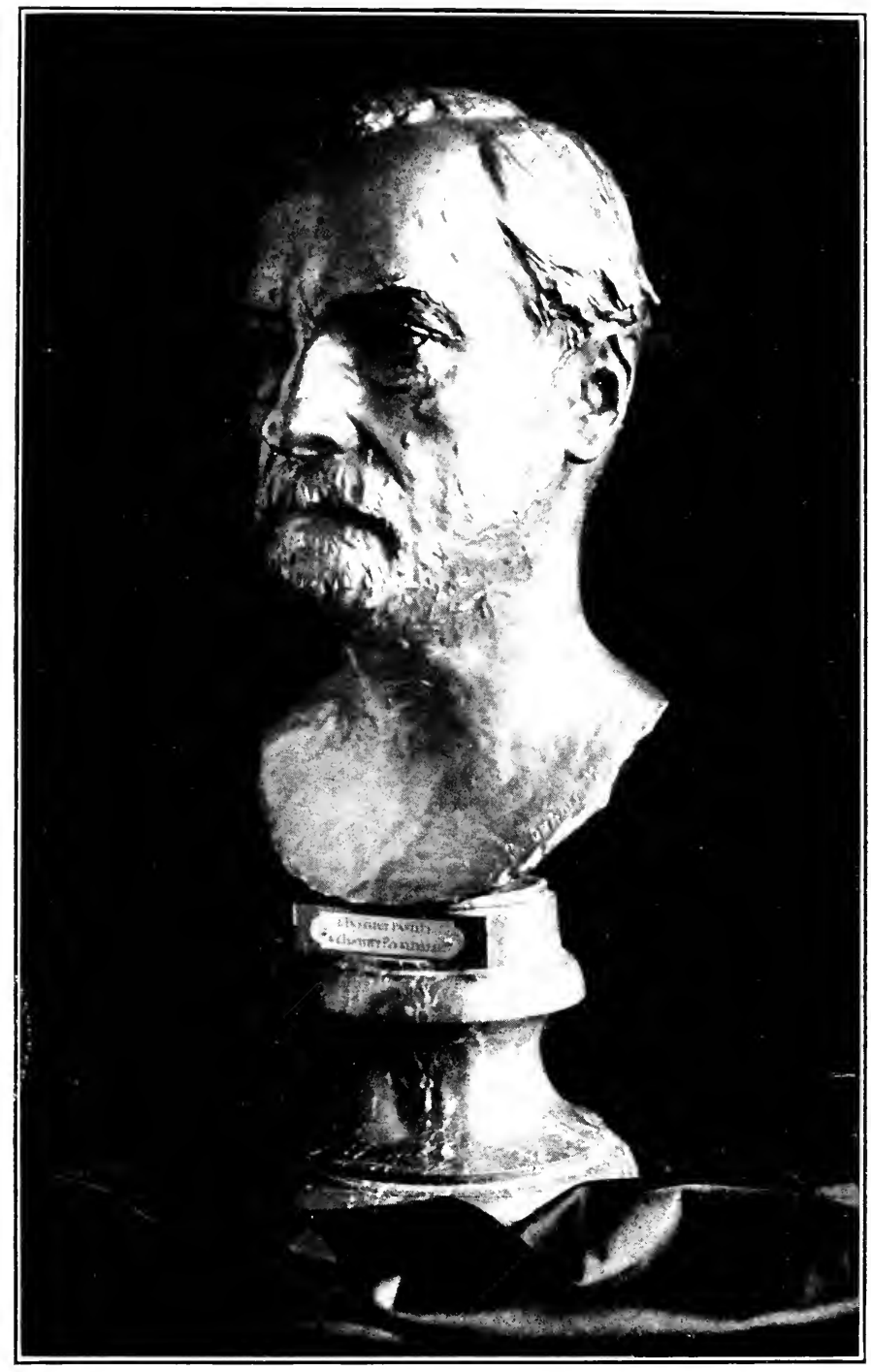

\section{IOUIS PASTEUR}

Bust presented by the Pasteur Institute of Paris, through the French Consul-General, to the Rockefeller Institute for Medical Research in New York, in recognition of the aid rendered by the latter to France during the epidemic of cerebrospinal meningitis in $19+49$. 


\section{THE CONQUEST OF DISEASE}

\section{THROUGH}

ANIMAL EXPERIMENTATION

\section{BY}

JAMES PETER WARBASSE, M. D.

SURGEON TO THE GERMAN HOSPITAL, BROOKLYN, NEW YORK; MEMBER OF THE AMERICAN MEDICAL ASSOCIATION, AMERICAN ASBOCIATION FOR THE ADVANCEMENT OF BCIENCE, ETC.; $\triangle U T H O R$ OF "MEDICAL SOCIOLOGY"

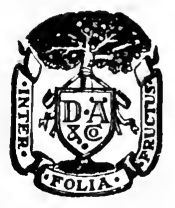

NEW YORK AND.LONDON

D. APPLETON AND COMPANY

1910 
Copyright, I9I0, By

D. APPLETON AND COMPANY

10 


\section{E D I C A T E D}

To the Laborers in the Fields of the Biologic Sciences, Who Wrest from Nature Her Secrets, to the End that Life shall be more Sweet, that Pain shall be Relieved, that Childhood, Youth, and Age shall be Absolved from the Hazards of Disease, that Death shall be Postponed, and that the Light of Truth shall Fall upon the Dark Places. 

Life is the loftiest consummation of all natural energy.

Human life should be the supreme object of human interest.

$\mathrm{He}$ sins who needlessly gives pain to any living thing. 



\section{PREFACE}

The general lack of information upon the biologic sciences has been responsible for much harm. Outside of the schools of science the teaching of these subjects is but meager. To most people the great world of animal life about them is filled with phenomena of mystery, or it is viewed with indifference. There is a particular dearth of information on the part of the public concerning the medical sciences. The meaning of physiology and how it is studied, the means by which medicine and surgery are advanced, and the principles of experimental medicine are matters upon which the public has little knowledge. Indeed, many of the students of these subjects accept information upon authority without knowing with what pains and labor it was secured. It is because of this that misunderstandings develop between scientific workers and the general public, and failures arise on the part of the latter to comprehend what the former are trying to do for it.

Some day the natural sciences will be taught more widely, and the world of facts about us will be understood by a larger proportion of people. The fundamental principles of the medical sciences should be a part of every one's education; and health and disease should be taught of as matters which are in the hands of the individual rather than as visitations of fate. At 
present the public is so poorly informed, that much of its supposed knowledge concerning health and disease represents the traditions which one misinformed person transmits to another, or is absorbed out of the ubiquitous literature of charlatanism. When there is a wider understanding of these things, and of the means by which medical knowledge is secured, there will be a more practical interest in public health and personal hygiene, charlatanry will be less profitable, and the strange cults, recruited from the groping, will be fewer.

This book is intended to give some information upon one of these branches of scientific work: namely, animal experimentation. It is based upon addresses on this subject given by the author before the New York Academy of Medicine, the Medical Society of the County of Kings, and the Brooklyn Institute of Arts and Sciences. These have been amplified and made into a little book, with the hope that it may be of service in correcting some misconceptions, and that it may elucidate in a measure one of the most important and fruitful fields of scientific effort.

In referring to certain experiments, the names of a few investigators are given. No attempt is made to mention all of the workers in any specific field. Names are given to serve as tangible links to connect the subject under investigation with the published reports. They must be regarded simply as illustrative, for in many instances the original authority is not given, but some later investigator is cited as serving better for illustrative purposes. 


\section{PREFACE}

The biologic sciences embrace all that has to do with life; but it is what they contribute to human life that makes them of importance. This book is concerned with the relation of these sciences to the life of man. 


\section{CONTENTS}

PAGE

I. The Study of Living Animals . . . 1

II. What is Meant by Animal ExperimenTATION • • • • • •

III. Animals Studied and the Technic $\quad 9$

IV. The Meaning of Pain . . . . . . 15

V. What is Cruelty to Ammals? . . 22

VI. Anmal Experimentation and PhysiOLOGY • • • • • • • • • • . 26

VII. Animal Experimentation and Practice of Medicine and Hygiene . $\quad 53$

VIII. Animal Experimentation and Surgery 121

IX. Anmial Experimentation and Diseases of the Lower Animals . . . 132

X. Conclusions . . . . . . . . . xiii 


\section{THE CONQUEST OF DISEASE}

\section{THROUGH}

\section{ANIMAL EXPERIMENTATION}

\section{I}

THE STUDY OF LIVING ANIMALS

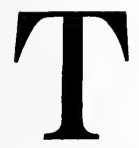

HERE is no knowledge so useful to Biologic man as knowledge of himself. Health knowledge. and happiness are promoted by it. Before the advent of the modern scientific spirit, biologic knowledge was required to conform to the dominant superstitions of the time. The human body was regarded as a peculiar and awful thing, and not amenable to the laws which govern the rest of the universe.

Then it was found that the mechanics of the body are entirely reconcilable with the 
The evo- principles of physics. Humanity's debt of lution of gratitude is incalculably great to those men knowledge. who at the risk of their lives and fortunes made dissections of dead bodies of men and animals, and discovered the mechanism of the muscular system which imparts motion to the joints, the valvular and pump-like arrangement of the heart, and the hydraulic principles of the tubes which convey the blood through the body. Then came those students of the secrets of nature who discovered that the same laws which govern man govern the lower and the lowest of creatures; that between soil and mineral, fluids and gases, plants and animals, there is no dividing line; that the lily is the daughter of the pool, and man is the brother of the ox. This knowledge was gotten for us, not by the philosopher among his books, but by the patient investigator who went to the heart of nature and studied her secrets. Out of these labors grew the biologic sciences; and modern medicine and hygiene were made possible. But the cost has been very great to these investigators. Humanity has ever been unkind to her greatest benefactors. From Andreas Vesalius, the first of scientific anatomists, persecuted to death, having committed no greater 
offense than that his researches showed that man has an equal number of ribs on either side, to Charles Darwin, whose offense lay in demonstrating the kinship of all animals, a large measure of contemporaneous contumely has been their lot. In the words of John Dewey, "Scientific inquiry has been the chief instrumentality in bringing man from barbarism to civilization, from darkness to light; while it has incurred, at every step, determined opposition from the powers of ignorance, misunderstanding and jealousy."

Even yet we fail to appreciate the value of the study of the biologic sciences; and I have no hesitation in declaring that future generaFailure to appreciate its value. tions will look back upon the pedagogic policies of this period with pitying wonderment. If there is educational culture to be gotten from studying the crimes and intrigues of potentates, there is also benefit to be derived from studying the battles of the leucocytes with invading bacterial hosts; if we must learn the origin and course of the Ganges and the Danube, so also may we with cultural profit study that of the great blood and lymph channels of our own personal dominions; if the moods and tenses of the Greek are indispensable to the 
cultured mind, so also are the modes by which typhoid and tuberculosis are propagated; if knowledge concerning the origin of words is important, so also is knowledge concerning the origin of our very bodies.

Life is the loftiest consummation of natural energy. Human life should be the supreme object of human interest. 


\section{II}

WHAT IS MEANT BY ANIMAL EXPERIMENTATION

The best of this knowledge which pertains to Biology the biologic sciences has come from the study requires of living animals. It is my purpose to deal animal with the human side of the question, although study. it should be borne in mind that the biologist, as well as the physiologist and physician, studies living animals of every kind under both natural and artificial conditions, and that zoology is advanced through these studies. The most active animal experimentation is being carried on by the biologists, who are studying animals of every species under many conditions. The progress and the teaching of biology are built upon the study of the lives of animals.

All animals are so closely linked by the bonds of kinship that information gained from one is applicable to the others. Something can Knowledge applicable be learned that has a bearing on man, from every living thing. The work which is being carried on by biologists in studying and exto man. 
perimenting in the physiology and pathology of animals is all applicable to man. Sometimes the value of this work appears in most unexpected quarters. When Ross discovered that the mosquito is the host that contains the plasmodium of malaria, his discovery connected two widely separated fields of biologic interest. The pathology of malaria in man had been well studied and was a matter of scientific record; and the biology of the mosquito, its anatomy, physiology, life history, and habits had been well worked out by the biologists. Now these two fields of knowledge are connected by the minute plasmodium, and the mosquito immediately comes into intensely practical importance with reference to man.

The flies and worms and many other lower animals are being connected intimately with the life of man; and the biologic sciences are becoming more closely knit together. Not only this, but the studies which the biologists are making in cellular generation, regeneration, mutation, and pathology among the primative animal forms are translatable to other animals and to man. Every biologic laboratory is an institution of experimental animal research.

By animal experimentation, from the more 
intimate human standpoint, is meant the examination of living animals for the purpose of observing and discovering the functions of organs; determining the effects of operations, injuries, or diseases; discovering the reaction of the body to medical substances; making diagnoses by injecting suspected materials; discovering the disease-carrying nature of the animal; manufacturing prophylactic, curative, or diagnostic sera; discovering antidotal remedies; practising surgical operations; experimenting with the view of finding means of accomplishing the extermination of harmful animals; and studying the nature of diseases which are common to both man and animals.

There is a general notion current that animal Errors experimentation means vivisection and that current. vivisection means the painful mutilation of animals. I was recently asked by a woman if I believed in "cutting up dogs alive." This question is about the same as asking if one believes in cutting up people alive. It implies gross mutilation, and even though a public executioner could be secured to engage in such a practice no useful knowledge could be obtained, excepting, perhaps, the revealing of the amount of disorganization, which an animal can 
endure; and the engines of war, commerce, and transportation, with their mutilations of human beings, have made it unnecessary for the scientist to perform such experiments. These notions belong with the traditional horror of the hospital and the mad house; they are the product of ignorance and prejudice. Practically all experiments performed upon animals are made by medical men or men allied with the collateral sciences; and I know of no class of men who have higher ideals of the humane and who are prompted in their work by more noble motives than they. Almost without exception these investigations are carried on under the inspiration of helping humanity. They require the best intellect of the trained scientific mind. Money reward plays but a small part as a motive in these studies. The same amount of intelligence and zeal applied in the getting of money would produce rich pecuniary results. It has been perversely intimated that biologic investigators are simply working for glory. Would that we might say as much of every one, for glory is no mean ambition. 


\section{III}

ANIMALS STUDIED AND THE TECHNIC

The animals used in these experiments repMethods resent practically all animals. The most com- of study. monly employed are sporozoa, fishes, frogs, mosquitoes, mice, rats, guinea pigs, chickens, pigeons, dogs, cats, cows, horses, monkeys, apes, and men. The great majority of experiments are in the nature of studies in the effects of feeding and breeding under certain conditions. These entail no operation or pain to the animal. A lesser amount of experimentation is in studying the nature of diseases of animals. In some cases these diseases are found naturally in the animal under observation, in others the animal is purposely infected. A lesser amount of work, but at the present time the most fruitful that is being carried on, is the inoculation of animals by the prick of a needle with bacterial products for the purpose of developing in their blood certain substances which are antagonistic to the bacteria. A still lesser, 
Operations. These operations are practically all performed with the animal under the influence of an anesthetic. The natural humanity of the operator not only prompts this but the success of the operation demands it. Scientific work might as well not be done at all as not to be done carefully. Comparatively little of this branch of experimental work is being carried on. A few surgeons are engaged in formal experimental operations upon animals. These are surgeons who are perfecting operative procedures on animals under anesthesia, for the relief of human ills, and who freely publish for the benefit of the whole profession the results of their work.

In physi-

The technic of experiments upon animals varies with the nature of the experiment. In physiology, if the object is to discover the functions of an organ, this is done by exposing the organ, let us say, for example, a glandular structure such as the thyroid or spleen. Then the condition of the gland is observed under various circumstances, as, after feeding, during digestion, or at rest. Its secretion is secured and examined chemically. The blood in the 
artery which enters it is examined and compared with the blood in the vein which leaves it. Certain substances are found in the latter which are not present in the former and which are also found in the gland itself. These substances, therefore, are regarded as internal secretions of the organ. Attempts are made to isolate these substances in the chemical laboratory and to discover their nature and composition. They are injected into another animal to observe what effect they have upon its bodily functions. Another operation is done at which the organ or part of the organ is removed, and the effects of its removal upon the animal economy is observed. If the removal of the organ results in profound disturbances, its internal secretion, secured from another animal, is fed or injected and the results carefully noted. Good results being secured an attempt is made to transplant from another animal the whole or a part of the organ in question in order to see if it is possible to restore to an animal, affected with damage or loss of this organ by disease, the secretion which is necessary for its economy. The laboratories of the physiologists who carry on such studies are equipped with the most exact instruments for determin- 
ing the bodily functions-instruments for testing the pressure of the blood, the relation of the intake of foods to the secretions, the character of the nervous reflexes, the weight of the animal, the composition of the air which it exhales, and innumerable observations of a similar nature which scientific accuracy demands. The physiologists of the whole world freely publish the results of their studies, and work in coöperation, one taking up a line of research where another has left off, and carrying it on. Thus all of the information concerning the functions of a certain structure does not emanate from a single source but is collected from observers all over the world.

Teaching purposes.

Another use made of living animals is the demonstration for teaching purposes of the functions of organs. Let us take for example the heart. An animal such as a calf is anesthetized with ether, the breast bone is removed and the heart exposed. After the demonstration the anesthetic is continued in an excessive amount and the animal killed. It is a wonderful sight to see the living heart in operation, propelling the life-giving stream through the body. Its action cannot be appreciated by examining the dead heart. When the heart 
of any person becomes the source of anxiety, if the man who stands by his side to render aid has seen the living heart in action, he is more competent to act wisely than he would be had he never witnessed this phenomenon.

Animals which are experimented upon for the purpose of studying diseases and poisons are inoculated either through the food or by giving a hypodermic injection with the material to be studied. The most commonly practised operative experiments are performed with the hypodermic needle, entail no pain, and require no anesthetic. The presence of pain in an animal makes cutting operations difficult, and anesthetics are always employed except in the rare instances in which the unconsciousness of the animal would defeat the objects of the study. In 1907 in England 73,000 experiments upon animals were made. Ninety-six and five-tenths per cent. of these were inoculations. In the remaining three and five-tenths per cent, anesthetics were used. Speaking before the Royal Society, Professor Starling said: "Though I have been engaged in the experimental pursuit of physiology for the last seventeen years, on no occasion have I ever seen pain inflicted in any experiment on a rab-

Experiments painless. 
bit, dog, or cat in a physiologic laboratory in this country." Twenty-five years ago Professor Gerald Yeo estimated that in one hundred experiments seventy-five were absolutely painless, twenty as painful as vaccination, four as painful as the healing of a wound, and one as painful as a surgical operation. At the present time not more than one experiment in one hundred thousand is actually painful. 


\section{IV}

THE MEANING OF PAIN

Let us not pass over this subject of pain, Pain chiefly dealing with this one case in a hundred thousand, without some further elucidation of a mata human attribute. ter which is much misunderstood. The human mind has a strong natural antipathy to pain. We shrink from pain in ourselves; it is repellant to us in others. One of the most depressing sights to the human eye is the witnessing of the infliction of pain. So strong is this instinct that few persons can by force of will overcome it even temporarily. Whether the pain is in man or in a lower animal we instinctively interpret it into terms of our own sensations and are accordingly depressed by it. But our knowledge of pain is derived wholly from human experience. The superficial parts of our bodies are supplied with sensitive nerves, and a general impression exists that this sensation manifested by the skin also prevails in the deeper parts. This is erroneous. Pain origi- 
nates in the sensory nerves which transmit certain sensations to the brain, which are interpreted as pain. These sensations can only originate in these particular nerves. Pain is not

Pain a special sense. a general sense which may come from every part of the body. It is a special sense, as much as smelling or hearing. The subcutaneous tissues, the muscles and organs are almost without sensation. An internal organ can be ruptured or a great muscle divided with little or no pain excepting when a sensory nerve trunk is injured. The brain itself is without sensation. A knife or needle may be inserted into the human brain, it may be lacerated or large pieces of brain removed, with no pain being experienced. Our horror of pain is derived chiefly from our knowledge of the skin and the mucous membranes which are continuous with it. This pain-appreciation is, moreover, dependent upon the mental development of the individual. Primitive peoples have an insensitiveness to pain which is beyond our comprehension. Their self-mutilations are made possible not by bravery but by this low degree of pain-sense. The savage who chops off his hand and presents it to the king has displayed a stoicism which is comparable to that of the 16 
fox who gnaws off his leg to get out of a trap. Neither one of them is much hurt. We must not interpret these things in terms of our own pain-sense.

The freedom from pain-appreciation posPain-sense sessed by the animals, lower than man, is wellin animals. known to the students of natural history, who see them chew off and tear off their members with nonchalance. After a severe surgical operation a rabbit goes to munching carrots as though nothing had happened. A horse with a broken leg will go limping about and continue to graze, carrying the dangling limb in a manner which in man would mean excruciating agony. The veterinary surgeon, in his operations upon cows, horses, and dogs, rarely bothers himself with anesthetic. He plunges a hollow needle through the skin, abdominal wall, and into the intestine of a cow to relieve a distended bowel without thought of anesthesia. The pain reaction may be as quick in an animal as in a man because in animals the nerve energy works largely through the spinal cord and inferior brain centers, and less is expended on thought. The prick of a needle may make an animal start as quickly as man; but, in order to judge whether it produces pain, we 
Interpretation of pain. must know what impression it makes on the consciousness or intellect of the animal.

In the case of man, pain-appreciation is not born with us, except in a very low degree. A new-born infant can be operated on without an anesthetic and show no pain. In fact there are certain operations habitually performed upon male infants which meet with less manifestation of pain than does an empty stomach. The human mind is so constituted that, a noisy demonstration, provoked by circumstances which in a highly developed man would cause pain, is interpreted as an evidence of pain. This human fault unhappily causes the rocking and jouncing of many infants which would be better left alone. The good-hearted mother knows that if she were making such a terrible, screaming demonstration as her infant, it could only have most excruciating suffering as a basis. Were the screaming of cats which assails our ears from the back yard at night to emanate from the physiologic laboratory instead of from the garden, visions of horrible tortures would rack the ignorant mind.

Facies pathetica.
Certain animals, notably the dog, cat, sheep, cow, and horse, have an expression about the eyes which is often strikingly similar to the 18 
expression assumed by the human face when appealing for pity. This is one of the accidents of anatomical structure. The elephant and many simians, though far superior to these in intelligence, have not this pitiful expression. This is responsible for much misunderstanding; as it is interpreted by the careless thinker in terms of human expression, when in fact it is most probable that the animal has no conception of pity or appeal and probably no idea that it is threatened with danger or pain. It is also just as true that a dog or cat will bite or scratch the hand that helps it as it is that it will lick the hand that harms it.

Nor can we interpret the so-called struggles of animals, under experiment without anesthetics, as evidence of pain. Experience has shown that they are mostly reflex. Passing from the brain and spinal cord are two sets of nerves, the sensory and the motor. In general one goes to the skin the other to the muscles. If the nerves or the spinal cord are divided the sensations of pain can not reach the brain and there is no pain, but still stimuli are capable of transmitting reflex motor impulses and causing motion. A horse can kick after he is dead. After a horse's head has been

Reflex movements. 
cut off, if the skinning process is begun at once, the animal will kick hard enough to break the knacker's arm. I have seen a dog with the spinal-cord divided make spasmodic movements of his hinder extremities and heard a bystander comment upon the evidence of suffering, when the movements were in no wise struggles prompted by pain. The person, ignorant of the physiology of the nervous system, thinks of a struggling animal as a suffering animal, not recalling to mind the struggles of a chicken with its head cut off. Pain is a psychic phenomenon, and lower men and animals have but little appreciation of it.

Operations painless.
Another point worthy of consideration in this connection is the painlessness of most operations even upon man. Physical pain is caused by certain abnormal pressure or irritation to sensory nerves. After the pressure or irritation is relieved the pain stops. In the ordinary operation, pain would be caused by the knife cutting through the skin. That is, the instant the knife presses upon a sensory nerve it causes pain, but as soon as the knife has passed through the nerve and ceases to make pressure the nerve is paralyzed and causes no more pain unless its stump be irri20 
tated. But all of this is done under anesthesia. After the wound is closed and dressed, there is rarely any pain. We hear much of people having undergone "painful operations," but investigation shows that they did not have any pain-they were under the influence of the anesthetic. The abdomen may be opened, the intestine sewed, or tumors removed, and when the patient comes out of the anesthetic there usually is no pain. The surgical ward of a hospital, where rows of people lie who have extensive wounds of vital parts, is not the scene of suffering that the novelists and attorneys for the prosecution often represent. 


\section{V \\ WHAT IS CRUELTY TO ANIMALS?}

Definition.

The question of cruelty to animals comes into the mind of every humane person when experiments upon animals are discussed. Let us first ask ourselves, what is cruelty? It may be defined as the useless and wanton infliction of pain. Are these experiments necessary?

Necessity for experimentation.

Is unnecessary pain inflicted? The answer is that if we are to understand the phenomena of life, the living animals must be studied. The anatomist may discover the existence of things; but we cannot know their function until we see them in action. The study of the living animal is just as essential to knowledge of life as the study of machinery in motion is to the knowledge of mechanics. A mere inspection of the assembled parts can not reveal how they will work.

Do animal experimenters inflict unnecessary and wanton pain? If an operation has been done that would have a painful result the animal usually is killed while unconscious. 22 
In the physiologic laboratory the condition of dogs after operation is not unlike that of their human brethren. They are comfortable and happy, playing about their kennels, and usually enjoying better care than has ever before been their lot. It has happened that experiments have been made upon animals which were painful and which have seemed to give no adequate return in information gained for the pains taken and inflicted. The results of these experiments are matters of record and no one knows but that some day they may be of use. Mistakes of judgment occur among all men, but, of all the cruelties inflicted upon living creatures, the least of these can be laid to the account of the scientific student of animal phenomena. It is impossible for us to put ourselves in the animal's place. If we try to do that, it is not the animal we are thinking about, but ourselves, with our sensibilities and our pains and likes and dislikes. Nor can we or do we apply to them the golden rule.

Concerning man's right to use animals for these purposes, his power and interest constitute his right. Society has agreed, so far as

Man's right over animals. man is concerned, that when the interest of the few conflicts with that of the many the few 
must be sacrificed. To preserve a nation men are sent into battle and sacrificed upon the altar of this principle. If our country were invaded by foreign foes we should go to war to kill them and to have many of our own killed, but it would all be for what we thought the general good. The individual afflicted with contagious disease must be deprived of his liberty for the good of the many. Majorities rule. Power dominates. Among animals this is the law: the strong prey upon the weak, the many upon the few, regardless of the question of benefiting either. But the inexorable laws of nature have made it salutary; and those which perish do so for the benefit of the strong and the more important.

Ethical motives.

Man should be actuated by higher motives, and should not destroy an animal unless its destruction is for his highest benefit. He should think of pain in two aspects-pain inflicted and pain prevented. These two should be weighed, one against the other; and the balance should always turn towards the latter. Of all the enormous destruction of animals which is now in progress on the face of the earth I know of none which is giving greater returns to humanity, in contributing to man's 24, 


\section{WHAT IS CRUELTY TO ANIMALS?}

health, his culture, his freedom from pain, and his happiness, animal for animal, than that practised in the interest of advancing the medical and biological sciences.

It is impossible to recount all of the discoveries which have been made through these studies. The whole science of physiology is founded upon them, and modern medicine owes to them the most important advances in the prevention and cure of diseases. 


\section{VI}

ANIMAL EXPERIMENTATION AND PHYSIOLOGY

Primitive

The old conceptions of physiology were born physiology. amid the superstitions of primitive folks. They had seen the organs of dead animals and people, but no serious investigations of their functions had been undertaken. At the height of the ancient European civilization the heart was regarded as the seat of the emotions, the liver was the organ that regulated the passions, the spleen was supposed to carry off the impurities of the body. It was believed that the heart was the acropolis of the body where the blood was prepared and from which it streamed out through the vessels to the various parts never to return. But the experimental study of living animals has eliminated the errors from the ancient speculations, confirmed the truths, and then added to scientific knowledge that great store of information which constitutes the modern science of physiology. Every 
department of physiology owes its best development to animal experimentation.

As the arteries are empty after death, Herophilus and Erasistratus (300 B. C.) originated the view that they contain air which is supplied to them by respiration. Galen (131 to $201 \mathrm{~A}$. D.) disproved this by a simple animal experiment. He wrote: "Whenever I injured an artery blood always flowed from the wounded vessel." He also tied a section of artery in a living animal between two ligatures and found it filled with blood. According to Plato, the speculative philosopher, the intestines were coiled many times in order that the food may not pass too quickly through the body and so occasion too soon an immoderate desire for more; for, he adds, "such a constant appetite would render the pursuit of philosophy impossible."

Later even more absurd functions were attributed to the organs. During the first fifteen hundred years of the Christian Era the most preposterous notions of physiology existed, being founded upon the sacred writings and superstitions of the saints. Spontaneous generation was looked for everywhere. The slight . glimmerings of truth as found in the writings

Early

Christian physiology. 
of Aristotle were cast aside, and in their place for a thousand years the "Physiologus" and the "Bestiaries," mingling scripture, legends of the saints, and pious inventions, were the authorities: the basilisk killed serpents with its breath; the pelican fed her young with her own blood; certain birds were born from the fruit of certain trees; the cubs of the lion remained three days dead after their birth and then came to life; animals could be created by a fiat. As late as the seventeenth century it was believed that mice developed out of corn and grains in dark places in the cellar. The lungs were regarded as a bellows for cooling the blood. The blood was supposed to flow and ebb back and forth through the veins.

The circu-

Anatomic sources of physiologic information lation of the blood. were not reliable. While Vesalius was familiar with the centripetal direction of the blood through the veins, it remained for William Harvey, who had been a pupil of Fabricius (1604), to demonstrate the complete circulation of the blood (1616-1619). He published his great discovery in 1628 ("De Motu Cordis et Sanguinis") ; but for ten years or more before that, he had been making dissections and discussing the subject in order to be sure that 
he was correct. He learned of the action of the heart, and the propulsion of the blood away from the heart through the arteries and its return to the heart through the veins, by his dissections of living and recently dead animals. The study of the blood-vessels of dead animals had deceived investigators for two thousand years. When he finally announced his discovery it met with strenuous opposition, and its correctness was a matter of discussion for twenty-five years.

How the blood passed from the arteries to the veins was not known to Harvey. Malpigi (1661), the founder of pathologic anatomy, discovered the capillary circulation. The conclusive demonstrations remained for Leeuwenhoeck (1674) who, with his microscope, actually saw the blood cells streaming along in the capillaries in the web of a frog's foot spread out upon the stage of his microscope. This was one of the earliest uses of the microscope, and completed the chain of evidence, which established the knowledge of the circulation.

By experiments upon living animals Galen, about $200 \mathrm{~A}$. D., discovered that the arteries contain blood; Harvey, after fifteen hundred years, discovered the motion of the heart, 
pumping out and receiving back its blood; and fifty years later the circuit was completed by the discovery of Leeuwenhoeck. The last discovery marked the beginning of modern physiology upon which medicine and hygiene are founded. When we consider the number of deer shot by huntsmen, who will begrudge science the few deer that Harvey sacrificed in the hunting park of Charles I to demonstrate the circulation of the blood?

Harvey experimented on himself.

Before leaving Harvey, it is worthy of note that he was a pioneer in the study of infective sepsis, using himself for animal experimentation. He says. - "I have myself, for experiment's sake, occasionally pricked my hand with a clean needle, and then having rubbed the same needle on the teeth of a spider, I have pricked my hand in another place. I could not by my simple sensation perceive any difference between the two punctures: nevertheless there was a capacity in the skin to distinguish the one from the other; for the part pricked by the envenomed needle immediately contracted into a tubercle, and by and by became red, hot, and inflamed, as if it collected and girded itself up for a contest with the poison for its overthrow." 


\section{EXPERIMENTATION AND PHYSIOLOGY}

There was a great predecessor of Harvey Michael whose name should be mentioned whenever the Servetus. discovery of the circulation is discussed: Michael Servetus, born in 1509. Servetus was a student of theology, doctor of medicine, and philosopher. He made dissections and venesections, and discovered, as a result of his observations of the values of the heart and the blood vessels, that the blood went out through one set of vessels and returned through the other set. He published his discoveries in a book entitled "Christianismi Restitutio." He described the flow of the blood from the right ventricle of the heart, through the pulmonary artery to the lungs, and from the lungs through the pulmonary veins to the left ventricle, showing that the "spirits" of the blood do not pass from the right ventricle to the left through the septum of the heart as was commonly believed. This great man was burned alive at the stake at Geneva, October 27, 1553, at the age of 43, by order of John Calvin. The whole edition of his work was ordered burned with him. Only about five copies escaped the hands of the Christian church; and, these not being found by scholars, the world remained in ignorance of the circulation of the 
Later

studies of the blood.

Transfusion and infusion.

blood, for three-quarters of a century longer, when the mechanics of the circulation were worked out again independently by Harvey, who knew nothing of the labors of Servetus.

Following Harvey, there came a steady series of additions to physiologic knowledge based on the study of living animals. Blood pressure was first studied by Stephen Hales (1727). He introduced a long glass tube into a blood vessel of a living animal and observed the height to which the blood column rose. To the femoral artery of a horse he attached a tube nine feet long. These experiments showed the contractile power and elasticity of the arteries, a knowledge of which is quite as important as a knowledge of the contractile power of the heart in order to understand the motive force which propels the blood stream. The experiments in the transfusion of blood were made upon animals before being applied to man. As early as 1556 Cardanus had suggested transfusion. Potter in England (1638) experimented upon animals with this operation, being stimulated by Harvey's discovery. Boyle and Lowes conducted similar experiments, bleeding animals and then reintroducing into their vessels blood from other 
animals. The first transfusion in man was done by Jean Denis in Paris (1667). He used the blood of a lamb.

From these beginnings, transfusion and infusion have been studied until the subject is now upon a practical basis, and in every large hospital in the world lives are being saved which otherwise would be sacrificed to hemorrhage. The innumerable accidents and diseases which cause loss of blood have had one of their greatest dangers met. Artificial blood, a sterilized solution of the normal mineral ingredients of the blood serum, is always on hand in every hospital; and this is readily introduced into a vein in the arm to take the place of lost blood.

Blood pressure, particularly in relation to shock, injuries, and surgical operations, has been studied by Crile, who has supplied information which is being applied in operating rooms in all parts of the world to the end that shock is minimized and lives saved. One of the most important gifts to humanity from the hands of this man is the operation of the direct transfusion of blood from one person to another without exposing the blood to the air or without permitting it to come into con- 
tact with anything but the normal lining of the blood vessels. The perfection of this operation has been accomplished after years of patient experimentation. In the older operations of transfusion it was found that the blood of one species of animal if introduced into the circulation of another species often caused destruction of the red blood cells, and had to be abandoned. Blood from which the fibrin and red cells had been removed was then employed with some success and much difficulty. It was to overcome these objections that Goltz, Kronecker, Sander, and Ott experimented with the salt solution already mentioned. But the perfection of procedures remained for Crile, whose technic permits the blood of a healthy father to be given to his son without permanent harm to the former. Not only in case of the acute anemia of hemorrhage is this operation of use, but also in many other conditions in which healthy blood can be of service in replacing that which contains poisonous materials. This operation, now in use but a few years, has already resulted in the saving of a number of human lives exceeding the number of dogs used in its discovery. 
The knowledge of the physiology of the respiratory system is founded on animal experimentation. Galen early in the first century observed that the diaphragm was the chief muscle of respiration. He divided the spinal cord of animals higher and higher and found that as his operations ascended paralysis of the intercostal muscles passed upwards. The Hon. Robert Boyle (1670) experimented upon rats, birds, frogs, fish, snakes, and insects, and showed that atmospheric air was necessary for their existence, and that vitiated air must be replaced by fresh air. Mayo published experiments in 1668 and 1674 showing that the respiration of mice diminished the amount of air by seven per cent. A hundred years later Joseph Priestley discovered oxygen. He then experimented upon mice and showed that by enclosing a green growing plant with the mouse the plant restored to the air the gas which the animal consumed, and thus established a complementary relation between animal and vegetable life.

This experiment of Priestley's was the beginning of the knowledge which is now prompting the preservation of the forests in civilized countries. Man began then to realize 4 
that the trees are his allies. Priestley was a great chemist who loved his fellow men as strongly as he loved the truth. A Birmingham mob, urged on by the clergy of the Church of England, wrecked his house, destroyed his valuable library, scientific instruments, notes and papers, attempted his life, and drove him into exile.

Then Lavoisier discovered that respiration is characterized by the absorption of oxygen and the exhalation of carbon dioxid. Animals absorb out of the air oxygen, they exhale into the air carbon dioxid; plants absorb out of the air carbon dioxid, they exhale into it oxygen. Animals inhale oxyen, combine it with the carbon of their tissues and food, and exhale from their lungs carbon dioxid gas. The trees absorb the carbon dioxid from the air through their leaves, appropriate the carbon to their structures, and throw off the oxygen. Each requires what is a waste product of the other.

Borelli (1679) gave the first accurate account of the mechanism of respiration. The chemistry of respiration could only be known after the study of the gases involved. Joseph Black in $\mathbf{1 7 5 7}$ discovered carbon dioxid in the expired 
air of animals. Lavoisier discovered nitrogen (1775) and the composition of the air but he believed that the carbon dioxid and the water which were present in the expired air were due to combustion of gases in the lungs. Vogel and Hoffman found an excess of carbon dioxid in the venous blood and an excess of oxygen in the arterial blood, and physiology stood upon the threshold of an understanding of the principles of respiration. Later Magnus extracted and analyzed all of the gases of living arterial and venous blood. Caisson disease is now understood. To gain this knowledge animals had to be sacrificed. The mechanics and chemistry of respiration being understood, artificial respiration and the resuscitation of the apparently drowned and asphyxiated became an easy step.

The struggle which man has had in order to Digestion. acquire an understanding of the physiology of digestion bears witness to the zeal for the truth which is implanted in the human mind. To begin with Spallanzani:- He caused hungry animals to swallow small pieces of sponge enclosed in perforated lead capsules, and after a time, when the sponges had become saturated with gastric juice, he removed them from the 
stomach. As early as $\mathbf{1 7 8 6}$ he asserted that the saliva had a digestive function. He subjected foods outside of the body to the action of these juices and observed the effects. Then an American physician, William Beaumont, in 1825, began a series of observations which attracted the attention of the whole scientific world. The animal employed by him in his experiments was a man, one Alexis St. Martin, a hunter and trapper. 'This man had an opening in the front wall of his stomach made by a gun-shot wound, which resulted in a permanent gastric fistula. Various substances were introduced through this opening into the stomach and the effects of digestion observed. Beaumont held séances with St. Martin and the hole in his stomach day after day and published for the benefit of his brethren the results of his observations. He not only discovered the digestive effect of the stomach juices upon the various foods but he studied the length of time that foods remained in the stomach and the peristaltic action of that organ. Following this, physiologists made gastric fistulas in dogs and were able to control absolutely these studies. Now in the physiologic laboratory we find a $\operatorname{dog}$ with a gastric fistula, that is, 38 
with a little silver tube opening into the stomach and closed with a cork; and the dog always seems proud of its possession. The brilliant studies of Pawlow, of St. Petersburg, made upon animals, have resulted in an understanding of the laws governing the secretion and action of the digestive juices. It was he who placed upon a scientific basis our knowledge of the influence of the mind and nervous states upon digestion.

Experimental studies of digestion have resulted in the identification of the digestive ferments and an understanding of their action. The effects of alcohol, tea, and coffee, and other fluids have been carefully studied. What has been done with gastric digestion has also been done with the digestive process in the intestine. The researches of Meltzer, Cannon and Herter of America, of Bayliss and Starling of England, and of many other physiologists, have placed the knowledge of the physiology of the intestines upon a scientific footing.

The knowledge that has been acquired concerning the liver, the pancreas, and the other digestive organs is very great and of much practical value in the prevention and treatment of diseases. The functions of the 
liver were never known until studied by animal experimentation. Concerning the pancreas, researches have been going on since 1664 when de Graaf made a fistula on a dog and studied the pancreatic secretion. Now a vast literature is required to contain what has been learned of it. The researches of Mering and Minkowski are triumphs of scientific method. Its diastatic action upon starches and sugars, its tryptic action upon proteids, its fat-splitting and fat-emulsifying action, and its milk curdling function, have all been followed out to an almost ultimate degree.

Studies of the pancreas have shown that this organ has important functions besides the secretion of its digestive juice. If the pancreatic duct is made to empty its secretion through a fistula outside of the body the animal does not die; but if the pancreas is removed and pancreatic juice is supplied to the intestine from another source the animal does die. The animal lives of the gland is removed and then implanted under the skin in some other part of the body. The substances which the pancreas supplies to the blood are essential to life. These substances have to do with the metabolism of sugar. When, as a result of 
injury or disease, the function of this gland becomes much impaired sugar appears in the urine. A man sustains an injury to the abdomen and sugar appears in the urine; before animal experimentation had shown this relation it was never suspected that this sign meant injury of the pancreas.

During the development of these studies many interesting and puzzling questions have arisen. John Hunter asked, Why does not the stomach digest itself? This question was answered by theories until Bernard introduced the leg of a living frog into the stomach of a dog. This was followed by the experiment of tying certain blood vessels of the stomach, shutting off the circulation from certain areas, and observing that the mucous membrane of these areas became digested. Out of these studies has come our understanding of the nature of ulcer of the stomach, which is now treated with success never before attained.

The knowledge of the absorption of digested nutriment dates from that memorable day in Assimilation. 1662 when Aselli exposed the mesentery of a dog after a full meal and observed a network of curious white lines under the peritoneum passing from the bowel. These were absent 
in hungry animals. Subsequent studies showed them to be minute lymphatic channels through which the hydro-carbon foods were absorbed and conducted into the blood through the thoracic duct. Our best formulated knowledge of the relations of foods to nutrition has been secured through feeding experiments upon animals. The determination of nutritive values, the discovery of the rôle of sodium chlorid and other salts, and the actual nutritive requirements of the infant have been found by such means.

Now the physiologist takes an animal or a man; he measures accurately each food that he takes; knows the weight of the body; examines every excretion as to its chemical composition, even to the exhalations from the lungs; and is able to know the transmutations through which the nourishment passes; and by making measured tests of the strength of the muscles, including the heart, he can learn the value of foods. The relation of food to health and energy is now the subject of careful animal experimentation, and the day is near when we shall eat more wisely as a result of it.

This whole subject of internal secretions of glandular structures is being worked out 
slowly but surely by physiologic experiments. Internal It is discovered that all of the glandular struc- secretions. tures supply certain substances to the blood which are essential to the economy of the organism and which are independent of the gross secretions which were first studied. The pancreas, the kidneys, the female breasts, the ovaries, the testicles, among the organs which have a special secretory function; and the thyroid, the spleen, the pituitary body and the suprarenal capsules, among the ductless glands,-all have their important internal secretions. The removal or destruction by disease of a certain amount of these organs is followed by constitutional disturbances.

The thyroid glands, two small bodies lying in the neck on either side of the trachea, may be taken as examples of the ductless glands, $i$. e., glands which do not produce a fluid which is emptied out through a tube into some hollow viscus. They were originally thought to be unimportant and not to have any function. Then about fifty years ago the physiologist Schiff reported that when the thyroids are removed from dogs the dogs die with certain peculiar symptoms. Twenty-five years later the Swiss surgeon, Kocher, to whom has just 
been awarded the Nobel prize for service to humanity, reported that some patients from whom he had removed goiters developed symptoms similar to those described by Schiff as occurring in dogs whose thyroids had been removed. These conditions were found to be similar to certain peculiar diseases the nature of which had never been understood. About the same time similar observations were made in England and a commission was appointed to study this class of diseases which seemed to have a relation to destructive changes in the thyroid gland. From that time on the experimental studies made upon the thyroid gland have been among the most fruitful efforts of physiologic research.

Another organ, the physiology of which is of much importance, is the suprarenal capsule, an apparently insignificant little structure lying just above each kidney. They supply to the blood certain substances which have to do with regulating the contractile tone of the blood vessels, having a direct action upon the nervous centres at the base of the brain. Their removal, or injury in animals, produces certain symptoms, which are now recognized as the symptoms of peculiar diseases which are found 
in persons having pathologic conditions in these glands. Another little gland lying at the base of the brain, the pituitary body, about the size of a pea, is found to have vital functions of a similar character. The testicles and ovaries produce materials which have an important physiologic relation to the functions of the brain. The new knowledge that has been gained by the experimental study of all of these glands in different parts of the body shows that the brain is much under the influence of the other organs of the body. Now, when these glands become diseased or injured, surgery is directed to conserving as much of their structure as possible, and they are no longer removed in toto as was once the practice.

One of the important chapters in biology is that which deals with regeneration. It has

Regeneration. thrown light of incalculable value upon animal economy. Biologists found that when a hydra has been divided into two parts each part forms a new animal. Indeed, if the animal is divided in a certain way each part will develop a complete new individual, and to continue propagation along this line all one needs is a sharp knife. Spiders and crabs possess the power of growing new feelers and claws in the place of 
those which have been amputated. The snail can regenerate part of the head, feelers and eyes. Fishes reproduce fins. Salamanders and lizards can reproduce an entire new tail, including bones, muscles, and nerves. The triton reproduces an amputated limb, lower jaw, or eye. These facts are of much biological importance. Surgery makes use of this knowledge. Who knows but that we stand upon the threshold of epoch-making advances in their further application to man?

Embryology and eugenics.

The evolution of embryology has of necessity had to depend upon animal experiments. The study of the growth of the chick in the living egg represents one of the most valuable sources of knowledge. Breeding experiments with animals have been carried so far that the study of eugenics has become a science. If we were to apply to man the knowledge that has been made possible by experimenting in perfecting the breeds of animals, we might have a race which in health and form would transcend the conceptions of the gods of Olympus.

Before knowledge can be applied, it must be acquired. We are witnessing this even now in regard to tuberculosis and typhoid. For 
two hundred years men have been busy piling up knowledge concerning these two conditions until sufficient information has been accumulated, which if applied would make them obsolete diseases; but not until the present decade, has man taken real practical interest in its application. Now, out of this knowledge, often gained from most humble sources, a great and irresistible movement is in progress which will not cease until typhoid and tuberculosis have been driven from the face of the earth. Who shall say but that some day man shall also apply to himself the knowledge which he has gained in the experimental breeding of animals, and in some brighter day interest himself as much in the propagation of splendid men and women as he now evinces in the breeding of splendid horses and hogs.

We should not leave this subject of physiNervous ology without touching upon the physiology of system. the nervous system. It has been a slow struggle, this searching for the springs of our own highest functions. Slow because of the peculiar and extraordinary delicacy of the tissues involved; difficult, because of the deep-rooted superstitions and fanciful notions which had to be overcome. Galen in the second century 
demonstrated by experiments upon animals that the brain is the seat of the intellect. He also discovered that the nerves have special uses, some conveying feeling and others motion. But the dominant superstitions discredited the work of this great man and soon the physiology of the nervous system was surrounded by mysticism. It was not until the nineteenth century that Sir Charles Bell (1810) completed the studies begun by Galen. He experimented upon living animals and developed exact knowledge concerning the motor and sensory nerves. The difference in function between the anterior and posterior roots of the spinal nerves was thus discovered.

The earliest experimenters differentiated the functions of the cerebrum and the cerebellum. They made gross tests which showed the former to be the source of voluntary impulses, and the latter the organ of coördination.

Animal experiments were made by Flourens, Luciani, and Horsley to determine the functions of the cerebrum. After removing the cerebrum from a frog or a pigeon all voluntary motion ceases, but the animal possesses its reflexes and vegetative functions. It sits quietly in an apathetic state. It has the power 
to maintain its balance upon the most difficult places. If food is placed in its mouth it has the power to swallow and digest it. Its incentives only for initiative action are gone. If, on the other hand, the cerebellum is removed and the cerebrum is left, the animal has sense appreciation but fails in muscular coördination. Marshall Hall discovered that if a nerve passing to the spinal cord is stimulated, an impulse is reflected back through a motor nerve independent of the brain, and motion occurs even though the brain be absent or the spinal cord be divided.

Then it was discovered that the voluntary impulses to more certain muscles emanate from certain parts of the brain. Fitsch and Hitzig, in 1870, mapped out these areas in the dog's brain, by using electric stimulation. Landois and Eulenberg found that mechanical stimulation or irritation has no effect on the centers, but chemical stimulation, such as salt solution, has. Following this Jackson discovered that localized inflammation causes stimulation; and the local relation of epilepsy to these motor centers was established. The most careful and valuable work was done by Ferrier upon cerebral localization in monkeys. The brain 
of the monkey is so closely analogous to that of man that localization findings in one are of much help in understanding the other. Munk, Schaefer, and Sherrington also contributed the results of their animal studies to this knowledge. It was found that a certain area of the cortex of the brain originates the impulses which cause the motion of certain muscles. The place of origin in the brain of the whole nerve supply of the muscular system is now pretty well known.

In the lower animals these centers are located in the basilar ganglia; but as we ascend in the intellectual scale the motor areas seem to be transferred to the cortex and come more and more under the intellectual control. The paths of the nerves from these centers through the base of the brain to the muscles which they control have been worked out. Now when a person presents paralysis of certain muscles or groups of muscles, whether it is due to apoplexy, tumor, inflammation, or injury we are enabled to know the location and extent of the damage. So fully has this knowledge been worked out that the speech center and the center which controls the muscles of phonation, with the paths of their nerves, are known. The 
neurologist differentiates the location of the lesion between ataxic aphasia (that condition in which words can be remembered but can not be spoken) and amnesic aphasia (the condition in which words can be spoken but can not be remembered).

This scientific study of the nervous system has been founded upon animal experimentation. The discovery of the property of nerves has depended on it. Certain nerves are incapable of feeling pain; and others are highly endowed with this property. For example: the two nerves distributed to the face, which are known respectively as the trifacial and the facial, may be taken. They are alike in their external appearance, even under the microscope they have similar structure. By examining the trunks of these nerves in the dead body the anatomist could not detect an essential difference between them. But experiments conducted upon the living animal show that their actions are very different. The trifacial is a nerve of sensation and supplies the face with feeling. It is the nerve involved in facial neuralgia. The facial is a motor nerve and gives power to the muscles of the face. The old mistake of dividing a motor nerve, with 
the hope of relieving intractable neuralgia, is no longer made.

The knowledge of the degeneration and regeneration of nerves followed; and the functions of the sympathetic nerves were discovered. Cesalpinus (15\%1) found that interruption of the blood stream rendered parts insensible; Galvini (1791) studied the reflexes by applying electric stimuli to frogs' legs; Stephen Hales and Robert Whytt showed that the spinal cord is necessary for reflex movements; and Marshall Hall worked out the whole problem of reflexes. The discovery of the nervous mechanism controlling the heart and circulation, and the demonstration of the nervous influences controlling secretion depend upon animal experiments.

Out of these studies has grown the necessity for instruments of precision; and we have to thank physiology for many of the methods of making examinations of the sick which enable us to differentiate them from the well. The greatest precision is demanded by the physiologist in his studies; and the diagnostician is able to apply the same methods to man. 


\section{VII}

ANIMAL EXPERIMENTATION AND PRACTICE OF MEDICINE AND HYGIENE

What knowledge has been added to the practice of medicine and hygiene by these methods? As we look over the list of diseases with which man is afflicted, and think of the studies which have contributed to their elucidation, it is difficult to find one, the understanding of which has not been helped by animal experiments.

The study of the infectious diseases is one of the most brilliant chapters in modern science. These diseases in man are found to be due to two classes of parasitic organisms, the bacteria and the protozoa. The bacteria are vegetable; the protozoa are animal. These microscopic organisms are capable of extraordinary proliferation, multiplying in a manner almost exceeding the power of calculation. They grow in the warmth of the body and take their nourishment from the substance of the body. Those organisms which produce dis-

Infectious diseases. 
eases do so chiefly because their excretions are poisonous to man. Their excretions produce toxins, and have the power when absorbed into the blood to cause the fever and other symptoms characteristic of the infectious diseases. The parasites are destroyed in the body by the white blood cells; and their destruction is hastened by their being overcome by certain other substances which are produced in the body as a result of the stimulation by the toxins themselves. This warfare between the bacteria and their products, on the one hand, and the leucocytes and body fluids, on the other hand, constitutes disease.

The symptoms of infective diseases represent the effort on the part of the body to rid itself of certain foreign substances. The natural tendency of these diseases is towards recovery. So long as the foreign microorganisms are present the white blood cells treat them as foreign bodies and operate for their destruction or elimination. Inflammation is the life-saving process, showing the effort of the body to limit their spread and summon its resistance to overcome them. Finally, the very presence of the toxins of the parasites themselves helps to render the body uninhabit- 
able for them; they, veritably, perish in their own excretions.

The fight goes on so long as the body has vitality; and the end of most infective diseases comes when the body has become sufficiently overwhelmed with toxic products to result in destruction of the invading parasites. In many diseases, so well balanced are the vital powers of the human body, these phenomena require a certain specific time for each variety of infection. The parasites multiply until they have produced an amount of toxin sufficient for their own destruction; then the symptoms begin to subside and recovery takes place. The presence of these products in the blood causes an immunity against the bacteria which produce them. In the case of some bacteria it lasts for a lifetime. The development of this immunity by the body saves the human race from extinction.

The knowledge of infection and inflammation was once a matter of vague theory and dealt with "miasms," "humors" and "vital methods. spirit." Now the microscope, the development of the science of bacteriology, and the application of these two to animal experimentation have given us the positive information of these 
things. Infective organisms may be introduced into an animal, and then the battle between the parasites and the white blood cells watched with the microscope. The toxic substances are extracted from the blood and studied; the infective microorganisms are removed and cultivated artificially; the toxins of artificially grown organisms are introduced into other animals, and the symptoms of the disease reproduced; infected animals are injected with artificially prepared toxins, and the natural overwhelming of the infective agents hastened; immunity is secured by introducing the products of the bacteria into the healthy animal and rendering the fluids and tissues of the body obnoxious to their growth; and sterilized products of the microorganisms are injected to test the reaction of the animal to a particular infection, thus determining whether it is free from or suffering with a specific disease.

These are but a few of the animal experiments which are employed in connection with the infective diseases. Every one of these experiments, having been worked out upon the lower animals, has been applied to man with results of such great importance that the period 
of human life is being lengthened; and preventive and curative medicine has become one of the most beneficent forces within the grasp of man for the promotion of human happiness.

It was the study of animals by Darwin and his predecessors that gave the world the theory Darwinism in medicine. of evolution, which has been one of the greatest instruments for its intellectual and moral uplift that history records. It put man in possession of an understanding of his place in the universe, and did more to free him from the incubus of superstition and the dread of supernatural powers than any other agency. It lifted him from his grovelling attitude of supplicating fear to the upright position, and placed him squarely on his feet.

Now the further pursuit of these same methods of study and experiment are showing the relations of man and his parasites. Man, descended from the cold-blooded amphibians, has gradually developed a higher and higher bodytemperature. Every indication seems to show that one reason for this was to make his blood too warm to serve as a pabulum for the parasites which infested it. When the plasmodium of malaria or some similar organism found its way into the blood, the animal which perished 
was one whose blood continued to remain at a temperature agreeable to the parasite; but the animal which increased its temperature to a point which was obnoxious to the invading organism survived, propagated its kind, and transmitted to them the very peculiarities by virtue of which it had resisted the enemy. Fever, following infection, is a natural and salutary reaction. It has saved the human race from extinction; and it has been just as much of a protective influence against our microscopic enemies as the green color of the tree-toad, the white of the polar bear, and the sepia of the cuttle fish have been protections against the macroscopic enemies of these animals. Those which developed protective reactions survived; those which did not, perished.

Experiments upon animals are showing that while evolution, natural selection, is adapting the animal to overcome its parasites and enemies, the same laws also operate in favor of the latter. So far as the purely vegetative processes go, nature is as kind to the bacteria as to man; each becomes adapted to new conditions because the survivors transmit their adaptability to their offspring. The same natural laws apply to each. Any peculiarity, which 58 
preserves living things from death, whether in bacteria or men, tends to increase as the species grow older. The parasites are adapting themselves to the changing conditions of the animals upon which they feed, and are undergoing mutations even more rapidly than the more complicated creatures. Nature is impartial. Life is a contest between living things preying upon one another. But man will win, because, to his natural, physical, protective resources, he adds to the contest the ingenuity of his mind. He is studying his enemies by scientific methods, familiarizing himself with their modes of life, and seeking out their vulnerable points. $\mathrm{He}$ is carrying on experiments with them, raising them, breeding them, and killing them. As a result of these studies, many are now at his mercy, to destroy when he will; and he is still forging ahead in the battle for his life.

The parasites causing most of the infective diseases have been discovered. The principal Parasitic diseases. diseases which display the evidences of being due to infective parasites, the causes of which have not yet been found, are: measles, scarlet fever, yellow fever, small pox, typhus fever, and rabies. The principal infective diseases of man which are caused by known bacteria are: 
tuberculosis, typhoid fever, gonorrhea, pneumonia, diphtheria, septicemia, puerperal fever (child bed fever), cerebro-spinal meningitis, erysipelas, dysentery, cholera, bubonic plague, leprosy, anthrax, tetanus, and glanders. 'The principal infective diseases of man caused by known protozoa are: malaria, relapsing fever, syphilis, amebic dysentery, and sleeping sickness.

The scope of this book will not permit a full discussion of all of the diseases with which man is afflicted: some of the more important will be discussed.

Typhoid fever.

Let us, for example, take typhoid fever, a disease peculiar to man and not found naturally among the lower animals. What could they contribute to its study? In the first place we were never in a position scientifically to combat typhoid until its cause was discovered. This was accomplished by Eberth who isolated the typhoid bacillus and cultivated it artificially in a nutrient medium made of beef and gelatin. This is the first stage of the use of the animal in studying this disease. The study was made possible by sacrificing the cow. Pure cultures of typhoid bacilli are to be found growing in all bacteriological laboratories. In the second 
step in animal experimentation, man himself is the animal observed. There are a number of instances on record of persons having taken into their stomachs, experimentally, accidentally, and with suicidal intent, cultures of typhoid bacilli which were being grown artificially in glass tubes in the laboratory, or in the form of dejecta, and developed typhoid fever. Furthermore, Brieger has isolated the chemical substance secreted by the typhoid bacillus, and by injecting this substance into animals he has produced the fever, nervous symptoms, and other manifestations characteristic of the disease.

The most hopeful treatment of typhoid fever Vaccination is being worked out by animal experimentation. Prompted by the brilliant results obagainst tained from the use of diphtheria antitoxin, Pfeiffer, Fraenkel and Manchot prepared a sterilized liquid from the cultures of the typhoid organism and secured encouraging results from its use. Then Hughes and Carter used the blood serum of convalescent patients, which experiments were followed by Klemperer and Levy who used the blood serum of dogs after inoculating them with pure cultures. They found this serum capable of rendering: 
the guinea pig immune to infection and also of curing the animal when infected. The treatment was then tried in human typhoid, with encouraging results.

Following this Sir Almroth E. Wright prepared a vaccine against typhoid which was first employed in the British army, and is now coming into general use. He employed rabbits and guinea pigs to determine its potency. Two inoculations are necessary. The injections do not make the patient sick or require him to give up work. Immunity lasts from two to six years. It may last for a lifetime. All regiments leaving for the tropics are offered this inoculation, and each year a larger percentage of the soldiers are accepting it. Here are some of the statistics:- In August and September, 1905, 150 men of a single regiment were inoculated, of these 23 refused to accept a second inoculation. The regiment reached India, September 28. A month later typhoid fever broke out and during the following few months 63 cases were observed in the regiment. With but two exceptions the disease attacked only the men who had not been inoculated, and both of these exceptions were men who had refused the sec- 
ond dose. Careful experiments were made with the Second Batallion of Royal Fusileers in India in 1905 and 1906. The average strength of this regiment was 948 men. During the two years, 284 were inoculated with Wright's anti-typhoid vaccine. The regiment had a total of 46 cases of typhoid. Thirty-five of these were men who had not been inoculated, 9 had been inoculated. Five of the uninoculated died. None of the inoculated died. Another Indian regiment, the Seventeenth Lancers, in 1905, 1906, and 1907, inoculated about one-third of its men. During the three years it had 293 cases of typhoid fever. There were 44. deaths, with not a single death of an inoculated man. During the first half of 1908 in the largest seven Indian stations where careful records were kept, out of a total of 10,420 soldiers, 2207 volunteered for inoculation. Typhoid developed in two per cent. of the uninoculated and in less than one per cent. of the inoculated men. Forty-five deaths occurred. Five per cent. of these deaths were among the uninoculated; and one per cent. was among the inoculated men. These reports are given because they represent something of new and hopeful interest. Among the British medical 
officers who are carrying on these experiments are men who are experimenting upon themselves. Such animal experimentation is now being made by Dr. Harrison, of the Royal Army Medical College, who is working out a plan for the internal administration of typhoid vaccines. In the United States Army a medical board has strongly recommended antityphoid vaccinations, and vaccination is now offered to those who desire it. Already 2000 soldier's have voluntarily received inoculation. The German Army has adopted the same means of prophylaxis, and is pushing it vigorously.

The results secured by this method are steadily growing better as the technic is improved. At present the results which are being attained indicate that the inoculation with antityphoid vaccine is capable of reducing the mortality of typhoid fever one hundred times. In general, for one case of typhoid among the inoculated there are ten among the uninoculated; and for one death among the inoculated who contract typhoid there are ten among the uninoculated who contract typhoid. In other words, the uninoculated are ten times more apt to contract the disease, and it is ten times more apt to be fatal when they contract it, than is 
the case with the inoculated. That means that, if everybody in the United States were vaccinated against typhoid, instead of there being 400,000 cases of typhoid fever during the coming year there would be 40,000 ; and, among these 40,000 cases there would be 400 deaths. At present there are 40,000 deaths, annually among the 400,000 cases. Thus vaccination against typhoid might be looked to to save 39,600 lives a year in the United States, and prevent 360,000 persons from having the disease. And this work has only begun.

The final phase of animal experimentation in connection with typhoid fever, which may be mentioned here, involves an animal which has more to do with the disease than any excepting man. It is the common fly. Dating from the time of the Spanish war, medical men have been studying the relation of the fly to typhoid fever. Thousands of these animals have been sacrificed in these investigations; and the indictment against the fly is indefensible. The fly is a notorious seeker after decomposing material, and the infected emanations from a typhoid patient if accessible to the fly are soon alighted upon. Many studies of a fascinating and convincing nature have shown the feet of 
the fly loaded with typhoid bacilli, where they are known to have remained alive for a period of two weeks. Much of that disease in military camps has been traced to this agency of dissemination. The story of "the fly that does not wipe its feet" before alighting upon our food has interest for all of us. It is true that typhoid does travel with the wind because the wind carries this little animal, as the studies of Anderson and Dutton have shown.

Bacteria

Certain persons after apparently recovering carriers. from infective diseases continue to harbor in their bodies the infective organisms and unknowingly to disseminate the disease. These persons are called "bacteria carriers" and are a great menace. Typhoid fever, dysentery, bubonic plague and diphtheria are transmitted in this way. Typhoid bacilli have been carried about and the disease transmitted by individuals who have been for several years apparently well. Animal experimentation is used to discover the infective organisms in these people, and vaccination against typhoid promises to render their bodies uninhabitable for the typhoid bacillus.

Tubercu-

Tuberculosis was once thought to be a vague losis. consumption of the body through some peculiar 66 
inherited weakness. It was met by apathy and hopelessness. The whole modern view of this disease, prompting mankind to overcome it and stamp it out, has been made possible by animal experimentation. . Tuberculosis is so common in the lower animals that its scientific study has been accompanied with little difficulty since the discovery of the causative factor, the tubercle bacillus, by Koch in 1881 . The way for Koch's discovery was paved by the work of Klencke and Villemin, who experimented upon animals with infectious materials and proved its infectious nature. Since that time an entirely new light has been thrown upon the disease. The identification of this bacillus marked the beginning of its conquest. By virtue of Koch's discovery, the danger of tuberculosis from the dust of dried sputum is demonstrable, and the positive diagnosis of tuberculosis is made possible. The infecting power of flies which alight upon tuberculous expectorations is proved. By no other means could the tuberculous conductor who moistened his finger with his saliva have been convicted of handing out an infected transfer.

The disease is found in all of the domestic 
animals-in cows, pigs, birds, and even in fishes. One of the earliest animal experiments was the capturing of monkeys in their out-door homes in the forests and confining them in cages in zoological museums. From this experiment we learned that they die of tuberculosis. Most of the monkeys in captivity die of this disease. A similar experiment was practiced upon the Fuegians. When our missionaries went among these people they found a hardy race, living a simple life out of doors. The missionaries taught them that this was not nice, and had them build little houses to shut themselves up in the same as we do. When Senn visited these people he found the villages of little white houses, and in almost every house he found a huge Fuegian breathing away his life with tuberculosis, and the beautiful little cemeteries back of the villages models of conventional propriety and activity. This is animal experiment number two.

In 1886 Trudeau demonstrated upon animals the influence of favorable environment. Inoculated rabbits placed under the unfavorable influences of want of proper light, air and food perished of tuberculosis, while inoculated rabbits turned out in the open air with abund68 
ant food recovered with but slight traces of the disease at the site of inoculation.

When a surgeon has under observation a questionable case of tuberculosis, the diagnosis can be determined by inoculating a guinea pig with some of the products of the lesion. If it is tuberculosis the animal rapidly develops the disease. Many hospitals keep guinea pigs for this purpose, and the service which the little animals thus render to man is considerable. Tuberculin is also used for diagnostic purposes. One of the important investigations now in progress is that which has in view the determination of the relation between human and bovine tuberculosis. Can we and our children contract tuberculosis from the flesh and milk of tuberculous cows? The similarity or dissimilarity of these two forms of tuberculosis cannot be discovered without making scientific studies of the living animals and without sacrificing some of these animals in these studies. By the use of the products of the tubercle bacillus, injected into suspected cows, it is determined whether the animals have tuberculosis or not; and thus the danger of infection through milk is greatly reduced.

Experimentation is also being conducted 69 
with the view of producing an antitoxin against tuberculosis. The outlook is most hopeful. The study of immunity in other infective diseases leads to the hope that means for producing immunity against tuberculosis will come out of the researches which are now being carried on in that direction. Further knowledge of the toxins of this disease is constantly being secured; and there are abundant reasons for the belief that prophylactic and therapeutic measures, surpassing in importance those now in the possession of man, will soon be discovered.

Since the tubercle bacillus was discovered and it became known that the fight is against a specific microorganism instead of some vague constitutional weakness or hereditary susceptibility, the mortality of the disease has steadily declined. In 1886, 88,000 persons died in Germany of tuberculosis: that is 31 per 10,000. In 1906, 64,000 died: that is about 17 per 10,000 . The same conditions prevailed in most other countries. This is one of the reasons why the span of human life has increased six years during the past twenty years. Natural selection and the laws of immunity also, perhaps, are operating to reduce the mortality in this disease. 
The attention of the world is now directed Plague. to the plague, a disease which has been spreading from India where it has long been endemic. This is now known to be a disease of rodents, the infective organism being carried from one to another and to man by the agency of the flea. This knowledge has been worked out by painstaking research. The specific microorganism was discovered by the Japanese bacteriologist Kitasato in 1894. Five million persons have died of plague in India during the past ten years. The disease is as old as the history of the human race. It is described by DeFoe in his "History of the Plague in London." In the fourteenth century it swept from China to Norway leaving twenty-five million victims in its path. It has at different times since that visited nearly all great cities of Europe with frightful mortality. Until science discovered the cause and nature of the disease it was regarded as a manifestation of Divine wrath, and combated with supplication and prayer. The work which resulted in the understanding of the mode of infection has cost the lives of many rats and guinea pigs. The mortality of the disease in man is between 60 and 85 per cent. The bacillus of plague 
lives in the blood and lymph vessels of the rat and in the intestinal canal of the flea which bites the rat. This knowledge has made fighting the disease possible. It means the extermination at least of the rat. When the rat contracts plague he sickens and dies. Fleas require living blood. When their hosts have perished they seek men or other living animals, and so carry the infection.

An interesting experiment is made with guinea pigs. If the animals are put in little cages in a plague-infected room, the cages being two feet from the floor, the guinea pigs do not contract the disease. The flea can not jump two feet. But if the cages are hung two inches from the floor the animals develop the disease and die. In India when sick rats are observed leaving the cellars, the people either desert the house or seek the roof, for as soon as the last rat in the house is dead they are in danger of being sought by the starving fleas. In the fall of 1908 two little boys in California found a recently dead rat. They put it in a box and buried it. Within a week the family of seven persons fell ill. The rat was dug up and found to have died of plague. Father, mother, grandmother, and four children died. 
While this disease was being combated so strenuously on the Pacific coast by the Government authorities, a meeting of the business men of Oakland, California, was held to protest against the "antiplague fuss that was injuring business." When the plague was discovered in San Francisco the business men, newspapers and politicians strenuously denied its existence and strove in every way to discredit the men who patiently and effectively were combating the disease.

The disease is found enzootic in a little animal in the mountains of Asia. Beliatsky and Reschtnikoff discovered plague in this rodent, which is a sort of marmot, called Arctomys bobac. Plague is continued in Siberia, China, and northern India as an endemic disease by the fleas from this animal. It is possible that it may be a natural host of the Bacillus pestis; but it is more probable that several rodents are. Half way round the world from these regions, for several years, isolated cases of plague have been developing in Contra Costa County, California. During this time an epizootic disease has been noted among the ground squirrels. The Public Health and Marine-Hospital Service of the Government took hold of the mat- 
ter. By inoculating guinea pigs, it was found that many of the ground squirrels were infected with plague, their fleas carrying the infection from one to another. Already plague-infected squirrels have been found in eight other adjoining counties, covering an area of five thousand square miles. So long as the fleas remain with the squirrels, the human danger is not great; but when other animals, such as rats, dogs, and cats, which harbor fleas, and which live in close relation to man, become the hosts of fleas which have come from infected squirrels, the danger becomes a serious one. It is through the agency of these house-dwelling animals that the disease is most apt to be conveyed to man. Within the last few months in 1909, three cases of human plague have occurred in Alameda County, California, developing unexpectedly as isolated cases. A local laboratory, which is doing excellent work, has been established for the study of plague. It should command the admiration of every American. The workers protect themselves by being vaccinated with the prophylactic of Haffkine. Their efforts are not only of local importance, but are full of significance for the whole continent. Of this work, some day it 
may be said: "They stood between the living and the dead, and the plague was stayed."

The vaccine against plague has been made by Haffkine of a standardized suspension of dead plague bacilli, the use of which increases the resistance to infection. We are to be saved from this disease through the knowledge that has been secured by animal experimentation. To gain this knowledge has cost much labor. The lives of a number of scientific investigators have been sacrificed. These men go down to their graves, martyrs to humanity, but the information which they have wrung from nature is good for all time; and that is their best monument.

Studies of cholera have advanced our knowledge of this disease to the point where it can be intelligently met and combated. Its cause is the spirillum of Koch. Until modern quarantine regulations were adopted it was a worldwide scourge. An antitoxic serum has been perfected by experimenting upon animals and is now being employed in India with good results.

Diphtheria is one of the oldest diseases recDiphtheria ognized in human history. Its cause, the Klebs-Loeffler bacillus, was discovered in $\mathbf{1 8 8 4}$

Cholera. 
by means of animal experimentation. Since the cause of the disease has been found, it is now known that a large proportion of the cases formerly regarded as diphtheria were not diphtheria but a form of tonsilitis that was noncontagious. Diphtheria within the memory of most men was the mortal dread of mothers. The diagnosis of the disease is now made early and treatment promptly instituted. Prior to the discovery of the cause, diphtheria was on the increase on account of the increasing density of population. But as soon as it became possible to recognize the disease early and to distinguish true from false diphtheria, the mortality began to decrease. In $\mathbf{1 8 8 3}$, the year before the positive diagnosis of diphtheria was possible, in the largest eighteen cities in Europe and America, 97 in every 100,000 of the populations died of diphtheria. In 1893 this mortality in the same cities was 81 . In 1894 the mortality was 79 . Then antitoxin was introduced, and in 1904 the mortality from diphtheria in these cities had been reduced to 20. Thus it is seen that two great causes have combined to cut down the mortality of this dreadful disease to less than one-fourth of what it had been. 
Thirty years ago there were surgeons who were occupied performing tracheotomy upon choking children more than with any other branch of surgery. Then intubation was invented to take its place; but it was followed so closely by the discovery of diphtheria antitoxin that it has had little opportunity to demonstrate what it could do. Now these operations are rarely required. In the city of Baltimore in 1894 the mortality of diphtheria was 74 per cent.; in 1895, 71 per cent.; in 1896, 51 per cent. In 1897 antitoxin was introduced. In 1898 the mortality was 5 per cent.; in 1899 it was 4.6 per cent. In the city of New York in 1893, the year before antitoxin was introduced, there were 7000 cases of diphtheria with 2600 deaths, a mortality of 36 per cent. During the same year the mortality among children treated for diphtheria in the best hospitals was 34 per cent. In 1898 the mortality was reduced to 12 per cent.; and in 1906 it was 9 per cent. The statistics in New York City show that since 1902, among the cases treated with antitoxin furnished by the State Department of Health, the total mortality has been 5.9 per cent. Among those cases which received it on the first day of the disease the total mortality was only 1.5 per 
cent.; among those receiving it on the second day of the disease the mortality was 2.8 per cent.; among those receiving it on the third day the mortality was 4.6 per cent. and on the fourth, fifth, and sixth days it was 15, 19, and 18 per cent. respectively. This shows that it has been possible to reduce the mortality in diphtheria from 36 per cent. to $\mathbf{1 . 5}$ per cent. if antitoxin is injected early in the disease.

In New York City there have been 100,000 cases of diphtheria during the last eleven years. There are 27,000 children living in that city to-day who without the use of diphtheria antitoxin would have died during that time. $\mathbf{3 0 0 0}$ children annually in that city are being saved as the result of the new knowledge of diphtheria. These figures are practically identical with the diphtheria statistics of London, Berlin, Paris, Liverpool and other large cities. How has this been accomplished? First by the discovery of the bacillus of diphtheria by Klebs and Loeffler, which has made possible the diagnosis of diphtheria; and second by the discoveries of Roux, Behring and Kitasato that, the injection of the sterile blood serum of an animal that has been rendered immune to 
diphtheria renders the body uninhabitable for the diphtheria bacillus.

How was this knowledge gained? Klebs in his microscopic examination of the false membrane of diphtheria had noticed peculiar rod-shaped bacteria. Many other varieties of bacteria were also present. It remained for Loeffler to separate these bacilli and grow them artificially in pure culture. Having isolated and cultivated them in the laboratory, the next step was to learn if they would produce diphtheria. He rubbed some of the culture upon the mucous membrane of the throats of rabbits, and produced the characteristic false membrane, general and local symptoms of diphtheria, and death in these animals. Further studies showed that certain other bacilli in the throats of healthy persons had the appearance of the diphtheria bacillus; but their nonpathologic character was determined by subsequent experiment. It was also found that the real diphtheria bacillus often remained in the throat a long time after the individual had recovered from the disease-sometimes weeks and months. Persons were going about unknowingly carrying diphtheria among children. Such a case was found in a nurse, whose pres- 
ence in five different homes left a trail of twenty cases of diphtheria behind her and five deaths. Soon after the discoveries of Klebs and Loeffler, many of these apparently healthy bacteria carriers were reported. Now cultures are taken from the throats of convalescents, and the period of danger is positively determined.

Roux, working in the Pasteur Institute in Paris, found that in the cultures of diphtheria bacilli there was produced a virulent poison. He filtered this out of the cultures, and, guided by the experiences of Pasteur, sought to immunize animals by injecting a small amount of this toxin into their blood. Behring carried on studies in the same direction, beginning with small doses of the toxin and gradually increasing it until the animals became immune and could not be inoculated with diphtheria. A small amount of serum from the blood of animals thus immunized, when injected into another animal had the power of rendering it immune for several weeks. Then the serum was used in children, suffering with diphtheria, and good results were observed. Since that it has been found that the horse lends itself best for producing the antitoxin in large amounts. 
This method positively produces immunity, and when diphtheria breaks out in a family of children a very small injection absolutely prevents the well from contracting the disease. Its curative power is great in direct ratio to the earliness of its employment. Now it is used in all civilized countries. Already the number of lives saved by antitoxin in Europe and America amounts to one hundred thousand annually. It must be given early in the disease because it cannot repair damage already done; it can only check the progress of the disease from the time when it is given. It is important that the antitoxin should be pure and of a known potency. The amount of antitoxin in serums is now required by law to be tested upon animals before it can be sold.

These discoveries have cost the lives of a large number of guinea pigs and rabbits, and are the result of years of patient study and experiment. They are now subjecting a number of horses to the inconvenience of receiving an injection of micro-organisms into their blood vessels and having some serum drawn off at certain intervals. But these horses seem content, and look sleek and well, and take their daily exercise with as much apparent relish as 
some of their richly caparisoned brothers who have no more serious occupation than drawing a fluffy dame and a pug dog through Central Park.

Presently we shall forget about the scourge of diphtheria, as we have that of other conquered diseases, but the mothers are still living who can recall to memory the pitiful pictures of their dying babes and the toll of precious lives which their families paid.

Yellow

Yellow fever was one of the scourges of fever. the Western hemisphere. In the past one hundred years it has caused 100,000 deaths in the United States. Forty-one thousand people have died of it in New Orleans and 10,000 in Philadelphia. It was endemic in Cuba until animal experimentation discovered its mode of transmission and prevention. The animals experimented with were mosquitoes and men, although other animals of minor importance have been used. Reed, Lazear, and Carroll, three American physicians, have placed humanity under a lasting debt for their work with this disease. They, with a number of volunteers from the Hospital Corps of the United States Army, carried on investigations in Cuba, and identified a certain variety of mos82 
quito as the host of the yellow fever germ. This they proved by sleeping amidst the bedding removed from the bodies of yellow fever victims. So long as the rooms were screened against mosquitoes they were not able to contract the disease. They furthermore showed that if the mosquitoes could not have access to people with yellow fever the mosquitoes did not produce the disease. There remained but one link to complete the chain; would a mosquito that had fed upon the blood of a yellow fever patient convey the disease to a healthy man? Among the corps of assistants there were men who offered themselves for this final test. Both Dr. Carroll and Dr. Lazear permitted themselves to be bitten by mosquitoes known to be infected. Carroll recovered, Lazaer died. Reed and Carroll have since died, having been exhausted by their labors.

Read the letters of Walter Reed to his wife, written from the yellow fever infected camp in Cuba, in the long nights when he kept the vigil by the side of the men who were laying down their lives for you and me and our children, and judge if animal experimentation hardened

${ }^{1}$ Walter Reed and Yellow Fever. By Howard 'A. Kelley, McClure, Phillips \& Co., 1906. 
the heart of this brave and gentle man! These men gave humanity the knowledge which if applied will make yellow fever an extinct disease. Why did the French fail to dig the canal through the Isthmus of Panama, and why is the canal zone now a veritable sanitorium? The world now knows the answer. And why will it be possible in a few years to make the passage from the Atlantic to the Pacific without circumnavigating South America? Because Reed and Lazaer and Carroll made their experiments with mosquitoes and men amid the pestilential swamps of Cuba.

Malaria.

The story of malaria is the same. This disease is caused by a protozoan parasite injected into the blood by a particular variety of mosquito. The parasites enter the red blood corpuscles, grow to maturity and destroy the blood cells. Each new generation is matured in a certain cycle of time, usually forty-eight hours. There is no uncertainty about these organisms; they are easily studied by the microscope in all of the stages of their development. Their life history and habits are as well known as those of the elephant.

For centuries the Pontine marshes near Rome were known to be infected with malaria. 84 
It was thought to be an effluvium (mala aria) which pervaded the night air. Consumption is yet reaping its hundreds of thousands of victims because of the ancient dread of the night air. Walk through the streets at night and witness the bedroom windows closed against it. Malaria has been the handmaiden of consumption from time immemorial. It was perhaps a chief causative factor in the decadence of the Greek and Roman civilizations. Then some English and Italian physicians went into the malarial swamps and lived in little houses which were freely opened to the night air but screened against mosquitoes. The people of Italy assured them that they were going to certain death. But they lived in these swamps in perfect health. They caught mosquitoes and dissected them, finding abundant malarial parasites. Some of these observers took mosquitoes back to England, and there permitted the mosquitoes to bite them, as a result of which bites they developed in England malaria from which they had been spared in the Pontine marshes.

Cerebro-spinal meningitis is caused by a Cerebrospecific diplococcus which sets up an inflamma- spinal tion of the coverings of the brain and spinal meningitis. 
cord. The identification of this organism was made through experiments upon animals. The serum treatment of cerebro-spinal meningitis has been worked out by Dr. Flexner and his associates in the Rockefeller Institute for Medical Research in New York, and is saving many lives and sparing many children most distressing suffering. The lowest mortality from this disease during any year prior to 1907 was 58 per cent. The average mortality has ranged from 70 to 90 per cent. It was 73.5 per cent. in 2755 cases reported in New York in 1905. By experimenting upon animals Flexner developed an antiserum which was used by careful observers in hospitals in Boston and New York. Up to January 1, 1909, the mortality in cases treated by the serum was 29.6 per cent. The most recent reports from this serum show a mortality rate of 19 per cent., and this report includes the worst possible cases, some of which were moribund when they came under treatment. Prior to the use of the serum, Holt reported 61 cases in children under two years of age in his hospital service, of whom 55 died-a mortality of 90 per cent. With the serum treatment, he reported 11 cases under two years of age, injected 
before the fourth day, with one death-a mortality of 9 per cent. Among those injected later in the disease, the mortality was higher. At the present time, among groups of cases of all degrees of severity, hopeful and not hopeful, with the antitoxin the mortality is under 25 per cent.; among the same classes of cases not treated by antitoxin the mortality is $\mathbf{8 0}$ per cent. The efficiency of the antitoxin is being improved by constant experimentation. Dunn, of the Harvard Medical School, believes the value of this serum to be comparable to diphtheria antitoxin. Another serum for meningitis is in process of development.

Acute poliomyelitis, or infantile paralysis, Poliothe disease which leaves children with perma- myelitis. nently paralyzed muscles, is unknown as to its cause and mode of dissemination. Its effects are so disastrous that it is of much medical and social importance. Autopsies show a characteristic lesion in the spinal cord. No curative or preventive treatment is known. Recently it has been observed in epidemics in various parts of Europe and America, but sporadic cases seem everywhere distributed.

In 1909 Landsteiner and Popper published the first reports of successful inoculation of the 
disease from human beings to animals. They caused the disease in the monkey by injecting into the peritoneum an emulsion made from the spinal cord of a child which had died from poliomyelitis. The monkey became paralyzed in the lower extremities and died on the sixth day. The experimenters were not able to transmit the disease from this to other animals. In the same year Flexner and Lewis, working in the Rockefeller Institute for Medical Research, published a preliminary report of a series of notable observations. They caused poliomyelitis in monkeys by inoculating their meninges from the spinal cords of children who had died of the disease. These monkeys developed the characteristic symptoms. From them they inoculated other monkeys; and they have been able thus to continue indefinitely the transmission of the disease in a series of these animals.

With poliomyelitis thus in hand in the laboratory, the first step toward its conquest has been made. We may now begin to hope for the interruption of the long line of dead and crippled children, the victims of this once mysterious malady.

Syphilis.

One of the most disastrous diseases of man88 
kind is syphilis. The public takes little cognizance of this disease, but the physician sees it on every side. It affects the guilty and the innocent, and is an important cause of degeneracy, the paretic nervous diseases, and insanity. It effects all strata of society. Our ancestors have had so much of it that in modern civilizations a certain degree of immunity exists and the disease is less destructive and more curable than formerly. Civilization and syphilization are spoken of together. It is one of our important problems. Some of the most valuable knowledge of syphilis has been gained since recent observers have found that it is inoculable to certain of the higher animals. By the inoculation of monkeys several new measures for diagnosis and treatment have been discovered.

At the present time in Africa there is prevalent a remarkably fatal disease, sleeping sickSleeping sickness. ness. In six years in Uganda it killed 200,000 out of a population of 300,000 people. It has spread over the whole of the Congo, depopulated some of the most fertile parts of Africa, and is spreading up the Nile. It is due to a parasite which gains entrance to the blood of man by the bite of a peculiar blood sucking fly. 
A small quantity of human blood, containing the parasite, injected into an animal, causes the disease and death; and the same pathologic changes are found as occur in the brain of man.

The discovery by Forde in $\mathbf{1 9 0 1}$ of a peculiar wormlike, active body in the blood of a patient suffering from an "African fever" stimulated research. These organisms were repeatedly found and named by Dutton Trypanosoma gambiense. Dutton and Todd in 1902, working under the auspices of the Liverpool School of 'Tropical Medicine, discovered the relation of these parasites to trypanosomatic fever in man. Then Castillani discovered the same organism in the cerebro-spinal fluid of a victim of sleeping sickness. This led to the discovery by Bruce and others that trypanosomatic fever is simply the first stage of sleeping sick ness. In 1903 Bruce announced that sleeping sickness is due to the introduction of an animal parasite into the human blood through the agency of the tsetse fly. These discoveries have all been confirmed; and the organisms can easily be found in the blood of any case of this disease.

The disease was making such frightful ravage in Africa that Dr. Koch of Berlin, the 90 
discoverer of the cause of tuberculosis, went to Africa, and for half a year lived much of the time upon a lonely island, inhabited by crocodiles, and studied the disease. He experimented with flies and crocodiles, and found that the fly which carries the disease subsists almost entirely upon the blood of these reptiles. Methods for combating the disease are now being applied with a hopeful outlook.

There is no known instance of the disease being transmitted from man to man without the agency of the fly. The destruction of these insects seems to be an insurmountable difficulty, although measures for their elimination are being studied. It is easily possible to diminish their numbers in a given locality. But what is still more important is the segregation of the sick, screening them from the flies. 'This is now being done, with the coöperation of the natives and the tribal chiefs, so that the flies cannot become infected with the parasites. This at present represents the most hopeful method of meeting the situation, just as it does with yellow fever. Meanwhile search is being made for some drug which will be inimical to the parasites and not to the patient the same as quinine is to the protozoa of malaria. For the 
Trypanosoma.

Insects as carriers. discovery of such an agent monkeys and rats are now being used; and the prospects are bright that such a substance will be found.

Study of the Trypanosoma shows that it is responsible for many other diseases, and that it is a family of many species. The Trypanosomidce are protozoa, like the plasmodium of malaria. They are elongated bodies, provided with terminal flagellæ, by which they propel themselves through the tissues. They had been found in the blood of fishes, reptiles, birds and mammals. One of the species infests the grey rat; another causes the Indian cattle fever called "surra"; and another is the cause of the tsetse-fly disease. An enormous amount of research is being carried on with insects and these parasites, and the mystery of tropical diseases is being much illuminated.

Among other diseases found to be conveyed by flies are trachoma and "pink-eye." Grassi affirms as a result of his studies that flies can ingest the eggs of many of the common intestinal worms (tape-worm, round worm, pin worm) and defecate the ova in a viable condition upon human food.

The researches of Ross in Egypt, and Craig and Ashburn in the Philippines, indicate that 92 
the mosquito is the agent by which dengue is spread. The recent work of Ricketts in Rocky Mountain spotted fever, and of Deaderick in black-water fever, constituted notable contributions to the experimental observation of these diseases.

Malta fever has been exhaustively studied by a commission appointed by the Royal Society of London. It has been found that the Micrococcus malitensis is constantly present in the blood of persons suffering with this disease, that domestic animals are frequently infected, and that the disease is largely acquired by man using the milk of infected animals. An effective vaccine has been prepared from cultures of the organism.

Yaws, an infective disease common in tropiYaws. cal countries, has been found to be inoculable to the monkey, in which animal it is now being studied.

The history of small-pox should be known Malta fever. to all. It should be taught in public schools. Jenner and his victory over this pestilence should be as familiar to students as Wellington and Blücher and their victory at Waterloo. Some day they will be. The reduction of mortality in this disease by vaccination is so great 93

Small-pox. 
as to furnish to all the world an example of the preventive treatment of diseases. Smallpox which was once a pestilence is now rare, and could be stamped out absolutely if vaccination and revaccination were universally practised. We can not say what rôle animal experimentation played in the discovery of vaccination, for it is wrapped in the obscurity of antiquity; but in the development of modern vaccine, the cows which lend themselves to experimental study are many.

Vaccination for small-pox was popularized in England by Jenner in 1798. It came into general use in the early part of the following century; provision for its gratuitous employment among the poor was made in 1840; and laws for its systematic use were enforced in 1871. At the time of the introduction of vaccination two-thirds of all the children born in Europe were destined to have small-pox, and one-twelfth of all born died of that disease. It was as serious a scourge as tuberculosis now is. In London from $\mathbf{1 7 7 1}$ to $\mathbf{1 7 8 0}$ there was an average of 50,000 deaths from all causes to every million of population. Five thousand and twenty of these deaths were from smallpox. That is, one death in every ten was from 
small-pox. Then vaccination came into use. From 1801 to 1810 the number of deaths per million of population had dropped from 5020 to 2040. From 1831 to 1835 it was 830 . From 1854 to 1871 it was 388 . From 1883 to 1892 it was 73 . During these 121 years the total death rate from small-pox diminished 60 per cent. In England in $\mathbf{1 8 3 8}$ the death rate from small-pox was 1064 (per million); in 1884 it was 27 ; in 1889 it was 1 ; and in 1890 it was nothing. In Iceland in $1807,18,000$ deaths from small-pox were reported in a population of 50,000. The history of other countries has been similar to these: there have been the endemic presence of the disease, with its high mortality, and occasional epidemics, especially fatal among primitive unvaccinated people. The perfect success of vaccination has blinded people to its importance. In the countries compelling vaccination there are so few cases that the disease is little thought of. This is a disease with which cleanliness and hygiene cut no figure. It attacks the clean and healthy as well as the dirty if they have not been rendered immune by vaccination or by an attack of the disease.

The Royal Commission on Vaccination 95 
found that during a period in which the mortality from small-pox declined 72 per cent., the mortality from measles had fallen only 9 per cent. and that from whooping cough a little more than 1 per cent. There has been scarcely any diminution in the mortality from scarlet fever, (a disease, the cause of which has not yet been found) during the last one hundred years. In the hospitals where small-pox is treated physicians and nurses who have been successfully vaccinated and revaccinated do not contract the disease. Physicians and nurses have no such immunity against other infectious diseases. Medical men constitute a class which is particularly well vaccinated: in England, deaths among them from small-pox are 13 per $1,000,000$ as against 73 per $1,000,000$ of the general population. In scarlet fever, against which physicians have no special protection the figures are reversed; 59 physicians per $1,000,000$ die of that disease as against 16 per $\mathbf{1 , 0 0 0 , 0 0 0}$ of the general population.

While small-pox has become a rare disease in vaccinated countries this can not be said of countries in which vaccination is neglected. The Imperial Board of Health of Germany collected information, and found that there 96 
were in the Russian Empire in the five years from 1893 to 1898 a total of 275,502 deaths from small-pox; during the same period in Spain there were $\mathbf{2 3 , 8 8 1}$ deaths from smallpox; in Hungary there were 12,241 deaths; in Italy there were 11,000; and in Austria 11,000 -all countries in which vaccination is much neglected. During the same five years in Germany where vaccination is well carried out, with a population five times greater than Spain, there were 287 deaths from small-pox, and these were largely among persons of foreign birth who had not been subject to the vaccination laws of the country.

'There is a cult of people called "antivaccinationists." They are usually the same individuals as "antivivisectionists." Their psychology is described in a subsequent chapter. They are often victims of misinformation or ignorance. There are no scientific men among their ranks. The whole medical profession and all biologists, with a few exceptions among the uncultured, understand the value and importance of inoculations against small-pox.

The one contention which is correct is that there are certain dangers in the practice of vaccination. They are the dangers inherent in 
all wounds. Scratches from pins and splinters are much more dangerous. Every operation, however slight, has its dangers. But the hazard of vaccination is not so great as taking an anesthetic, having a tooth pulled, crossing the street, riding in a car, or going shopping. It is practically negligible when compared with the great benefit to be derived. A few unvaccinated persons in a community protected by vaccination are not apt to have small-pox; but if every member of the community were as neglectful of this duty to himself and society, the danger would become decidedly great. By care, any danger in vaccination can be reduced to nothing.

Wherever vital statistics are kept the immunizing power of vaccination is proved. In Germany, Austria, France, America, and Japan-the whole world-the results have been the same. Vaccination and revaccination prevent the disease; and persons so immunized are exposed to the presence of small-pox without fear of contracting it. To secure this immunity a large number of young heifers are subjected to the inconvenience of being scrubbed scrupulously clean, wrapped in sterile cloths, and occasionally strapped to a table to 98 
have their bellies shaved and scarified, and then visited by the bother of having their health and cleanliness protected while they graze-all more or less of a nuisance to a frisky heifer calf.

In eastern Europe, India and some other countries is found a disease called relapsing fever, due to a parasite which enters the blood through the bite of an insect. This disease can be transmitted to rats and other animals, in which it has been studied most successfully. Immunity has been produced experimentally, and curative sera prepared. Certain chemicals also have been found to have curative power.

There is a peculiar disease called myxedema, the nature of which until recently was unknown. It is characterized by a puffiness of the skin and by mental hebetude; and it defied treatment. It was studied by Sir William Gull. An independent worker, Sir Victor Horsley, making animal experiments at Brown Institute in London, removed under chloroform the thyroid glands from monkeys. $\mathrm{He}$ observed peculiar constitutional changes similar to those observed by Schiff. The animals became stupid and inactive and developed a strange puffiness of the skin. Schiff had cured

Relapsing fever.

Myxedema. 
the symptoms following removal of the thyroid by inplanting in the abdomen of the animal a piece of thyroid taken from another animal; but the cure was not permanent, as the transplanted gland atrophied and the symptoms recurred. Horsley had seen some cases of myxedema in man, and he at once associated it with the condition which he had produced in monkeys. Could it be possible that these people with myxedema were suffering from some disease that had destroyed their thyroid glands? Their symptoms surely resembled some of the symptoms displayed by the monkeys whose thyroid glands he had removed. He tried an experiment. He transplanted the thyroid gland of a sheep under the skin of a patient suffering with myxedema. To his great satisfaction the patient at once improved. The same operation was done upon other patients and they all improved. The improvement was but temporary because the transplanted tissue did not thrive well. Schiff and others injected the extract of thyroid into animals with good results. Now patients with myxedema are simply given the dried extract of thyroid gland by the mouth; and so long as they take it they keep well. These glands are 
secured from sheep, and compressed tablets of dried and powdered thyroid are now a common article of commerce. Marvellous changes in these people have been wrought by this treatment. Many patients who had formerly been committed to insane asylums are now enjoying health.

Cretinism, or dwarfism, is myxedema developing in infants born without the normal amount of thyroid. It is prevalent in Switzerland. They have the characteristics of imbeciles. It is a striking sight to see one of these children, with its drooping eyelids, half open, drooling mouth, and stupid air, converted in a few days into a bright-eyed healthy youngster. As a result of these studies it is now known that the thyroid is essential to life; that myxedema and cretinism are due to pathologic destruction or congenital inadequacy of this gland; that a small bit of thyroid left in the neck serves the physiologic requirements of the body; and that when all of the gland is removed or destroyed health can be maintained by feeding with a very small amount of sheep's thyroid.

As myxedema and cretinism are diseases Acromegaly of lack of supply of thyroid secretions, 101

Cretinism. 
acromegaly and giantism are diseases of overstimulation of the organism with this material. Berkley, Hirshfeld and others have found that the thyroid, pituitary gland, and adrenal glands are all linked together by a system of nerves. Howell, Schafer and Osborne have found that the secretions of these organs all have an interdependence. It seems that the thyroid secretion is essential for the stimulation of the pituitary gland and the energizing of the adrenal glands. These discoveries are leading to an understanding of some of the strange phenomena heretofore set down as derangements of the nervous system. Children which belong to the mentally deficient are found lacking in thymus gland; and we are now upon the threshhold of an effective treatment of these children, having as its basis the overcoming of the real defect instead of striving to whip into activity minds made dull by being overwhelmed with unneutralized toxins.

Addison's disease. Addison's disease is a peculiarly fatal condition accompanied by a bronzing of the skin and evidences of a severe toxemia. Many autopsies have shown that it is associated with disease of the suprarenal capsules, resulting in destruction of their secreting cells. Commonly 
this destructive process is due to tuberculosis. No cure for the disease is known. Busch, Leonard, and Wright have succeeded in transplanting from one rabbit to another this organ, and then removing the natural organs from the recipients. They have performed enough of these experiments to demonstrate the practicability of the operation, and we may hope that it may succeed when applied to Addison's disease in man.

Diabetes holds less mystery, than it did beDiabetes. fore the physiology of the pancreas was studied by Claude Bernard. Mering and Minkowski removed the pancreas from dogs, and found that the animals could not oxidize sugar; and the sugar normally formed in the body circulated in the blood, and was eliminated by the kidneys. It was found that if a small bit of pancreas was left in the body, diabetes either did not occur or was less pronounced than when the whole gland was removed. Minowski removed a piece of a dog's pancreas and transplanted it under the skin; later he removed the whole pancreas, and found that the dog's urine remained free from sugar for two months; and upon removal of the piece transplanted beneath the skin extreme diabetes 103 
developed. 'This diabetes, produced artificially in dogs, is similar to human diabetes. In each there is an inability to oxidize sugar, and in each there is present in the blood a poison called oxybutyric acid. In many cases of human diabetes, disease of the pancreas is found at autopsy; in some cases it is not found; but there are functional disturbances which neither the autopsy or the microscope can discover. This disease is responsible for over 6000 deaths annually in the United States. The experimental study of its nature is to be looked to as offering a hope that we shall some day know a cure for it. Already, the lessons learned from animal experimentation are being applied successfully in the interest of man.

Rabies.

Rabies, hydrophobia or lyssa, is a disease which makes an undying impression upon those who have seen it, but which is so horrible and bizarre as to seem unreal to those who have never witnessed its manifestations. The disease has been observed in the dog, man, fox, cat, wolf, jackal, hyena, badger, marten, horse, cow, sheep, pig, goat, antelope, deer, guinea pig, and rabbit. It prevails in all countries. In 1604 there was a severe outbreak in France. In the following century all of Europe suffered from 
it. Between 1779 and 1807 it came to America through the West Indies and Peru. In $\mathbf{1 8 6 0}$ hydrophobia prevailed so extensively in Ohio and Missouri that the farmers petitioned the Government for reimbursement for their great loss of cattle. In 1863 the disease was so prevalent in Greenland that in certain districts all of the dogs perished of it. The histories of the various epidemics is a most instructive study.

It is an old disease, being known to the ancient Egyptians. We find it described by Aristotle (384-332 B. C.) He said, "Dogs suffer from a condition of madness, which puts them in a state of fury, and all animals they bite when in this condition become also attacked by rabies." Cornelius Celsus, in the first century, gave an admirable account of the disease. Galen (131-201 A. D.) declared hydrophobia to be the worst of all diseases, and described the symptoms with great accuracy. Rhazes (922) and Avicenna (1036) observed and described it. Then scientific interest waned till the nineteenth century when the disease was more fully studied by Meynell, Youatt, and Hertwig, who endeavored to place the subject upon a more scientific footing. It had been believed by many that rabies could develop 
spontaneously in hungry dogs. Attempts to produce hydrophobia in dogs by starving them were made by Radi and Bourgelat, and were negative.

It was observed that the disease was most prone to develop in dogs that were given the largest measure of liberty. The idea that angry or excited dogs could cause rabies by their bite was held by the laity and is even now believed by the uninformed. Studies continued and the lines of observation were fast closing around the infectiousness of the disease. Thamhayn collected 19 cases, 18 of which were fatal, occurring in human beings who had been bitten by dogs which were apparently healthy but which subsequently became rabid. Then Hertwig made his experiments. He inoculated 30 dogs with the saliva of dogs either dead or suffering with rabies, with the result that 17 of the animals developed the disease. He made experiments to discover if the infection could be conveyed through the food or other intermediate vehicles, all with negative results. In no other way was he able to produce rabies; but he did find that many dogs are immune. Bollinger believes that it is possible for inoculation to be conveyed from the 
dog by fleas which are nourished by the blood of the dog and from which hardly any dog is free. It has been shown conclusively that this companion of the dog can convey anthrax and plague. Virchow insisted that rabies is an infectious disease. It remained for Pasteur to carry out studies which have conclusively proved its infectious character. His investigations have been continued by Roux, Negri and a large number of other biological students.

The disease causes the development in the nerve centers of certain structures called Negri bodies. The discovery of these confirms the diagnosis. Otherwise diagnosis must be made positive by inoculation. However, no anatomic finding is more characteristic than the symptoms manifested. Study of these animals shows that the dog to be feared is the one that has a listless expression, with altered voice and hanging jaw and tongue; he wanders about aimlessly, is restless, bites at imaginary objects, or sulks into a corner; often he display an unusual disposition to lick his master's hand or face. The disease seems often to spring up sporadically because infected dogs are prone to wander off, travelling often twenty or forty miles, and then dying in some corner, 
after having bitten another dog, cat, or child, which in turn may die without the real nature of the malady being recognized. Rabies is on the increase. Moore reports that at the New York State Veterinary College they have had sent for examination a rapidly increasing number of suspicious animals each year, from one in 1899 up to more than 200 in 1908. Over half of these were positively identified as rabietic. The others were negative or undetermined. There were 45 separate outbreaks of rabies in this state alone from January, 1906, to September, 1908, identified by the chief veterinarian of the Department of Agriculture.

During 1908 and the first half of 1909 in New York State, 89 persons are recorded as having been bitten by rabid animals, of whom 5 died; also 26 cattle, 36 sheep, 7 swine, and several hundred dogs have died of the disease during this period. The records of the Department of Health of New York City show a list of 46 persons who have died of rabies. Prior to the Pasteur treatment and the identification of the infectious nature of the disease, there were yearly in man in Prussia 5 deaths, in Austria 58 deaths, and in France 24 deaths.

What has been done besides making the 108 
studies of the nature of this disease? Accurate diagnosis has been established; and the treatment, worked out by Pasteur, is yearly saving many lives. Every large city now has a Pasteur institute for the treatment of hydrophobia. Since the inauguration of the Pasteur Institute in Paris in 1886, there have been treated 31,330 cases, of which $\mathbf{2 3 8}$ died. The highest mortality was .94 of 1 per cent. at the beginning, which has since been reduced to .18 of 1 per cent. Out of 4516 persons treated, who had been bitten by dogs in which rabies was positively proved, there were 34 deaths - a mortality of .75 of 1 per cent.

In the Pasteur Institute at Baltimore 632 of the first 1000 persons treated had been bitten by animals which were proved to be rabid by $(a)$ the development of rabies in rabbits inoculated from them, or by $(b)$ the development of rabies in other animals or human beings bitten by them. But two of the patients who completed the treatment for immunity died-a mortality of .2 of 1 per cent. At St. Petersburg 2000 people are treated annually.

Thus on the whole the mortality among persons bitten by rabid animals has been reduced from 10 or 20 per cent. to a fraction of 109 
1 per cent. Persons bitten on the uncovered hands or face are much more prone to develop the disease.

Not long ago rabies was so prevalent in Berlin that a new case in man was reported every day. The authorities ordered every dog to be muzzled and no dog to be at large without being led by a chain. Paris has done the same. Australia has become absolutely free from the disease by imposing a six months' quarantine upon every dog brought into the country. At a recent meeting of the New York State Veterinary Society, Dr. Moore said that if every dog in America could be muzzled for ninety days the country would be freed from rabies. The experimental study of this disease has shown its nature, has evolved a prophylactic which will save the life of the infected person, and now points the way to eliminate the disease. The destruction, muzzling and proper confinement of dogs, now successfully carried out in many places, which would wipe out the disease, is surely better than persisting in the necessity for Pasteur institutes. But so long as mad dogs are permitted at large the necessity for treatment will continue. Professor Felix von Niemeyer said that no one who expends sympathy 
on the poor dog, and petitions against his being tied up or wearing a muzzle, is so inhumane but that he would be cured of his consideration for the dog if he could but see one human being with hydrophobia. Besides, for every human being who dies of rabies there are a hundred times as many dogs. The interest of the animals also demands the elimination of the disease.

No man of modern times can be named whose benefactions to mankind have been Louis greater than those of Louis Pasteur. $\mathrm{He}$ laid at rest the theory of gross spontaneous generation, which for centuries had blinded the world. Besides his discovery of the cause of fermentation, he discovered that each infectious disease is caused by a micro-organism, and he discovered that the microbe of the disease could be cultivated under such conditions as to destroy its virulence and yet enable it to be used by inoculation as a vaccine to prevent the disease. Out of his discoveries grew modern antiseptic surgery and the antiseptic treatment of wounds inaugurated by Lord Lister. His discoveries also were the beginning of the treatment of infective diseases by bacterial products. He first

Pasteur. 
applied these principles in man to the treatment of rabies, and removed the dangers of this terrible malady. The conquest of hydrophobia by Pasteur is one of the most important events in human history. He studied anthrax in cattle and devised an antitoxin for its prevention, as a result of which France alone is saved annually $\$ 5,000,000$ worth of sheep and $\$ 5,000,000$ worth of cows. He discovered the cause and prevention of the rouget disease among hogs, the mortality having been twenty per cent. Pasteur reduced it to one and fivetenths per cent. He did the same with chicken cholera and the silk-worm disease. In the words of Professor Huxley, "Pasteur's discoveries alone in money value have been sufficient to make good the war indemnity of one thousand million dollars, paid by France to Germany." The conquest of diphtheria is due to Pasteur more than to any other man. His experiments were carried on with guinea pigs, rabbits, and dogs. If one is not sure of the beneficence of the work of this modest man, let him read the story of his life by Vallery-Radot. ${ }^{1}$ Every schoolboy should be familiar with

${ }^{1}$ The Life of Pasteur. By René Vallery-Radot. McClure, Phillips \& Co., 1906. 
it. The study of his activities has more educational value than the study of the activities of Napoleon. Pasteur was the ideal of honesty, kindness, and zeal for the truth.

Arterio-sclerosis, the hardening of the blood vessels by the deposit in their walls of fibrous tissue, constituting the chief symptom of old age, has been studied experimentally. It has been found possible to produce this condition in rabbits and other animals by administering to them the toxins which develop in the human intestine. Continuous poisoning with alcohol and tobacco has been found to have a similar effect upon animals. It was upon the basis of such experiments that Metchnikoff worked out his theory of old age, and found intestinal putrefactive bacteria to have much to do with this most fatal of all human diseases.

Snake bite in this country is of some imporSnake bite. tance, but in many of the tropical countries it is a great national question. There are twenty thousand deaths annually in India from cobra bite. Mitchell, of the United States, in 1860, investigated the nature of this venom, experimenting with rattlesnakes, frogs, birds, and other animals. His studies were followed by researches by English physicians in India who

Arteriosclerosis.

Snake bite.


have now perfected a vaccine against the deadly snakes of that country, and are using it with remarkable success.

Scorpion sting.

In Egypt the sting of the scorpion causes a large number of deaths among children. In Assouan, scorpions cause $\mathbf{1 . 6}$ per cent. of the total deaths. Wilson, of the Egyptian Government School of Medicine, found that animals which live in close relation to the scorpion, such as desert rats and ground hogs, develop a high degree of immunity. He also found that some people who live where scorpions abound become immune, and it is reported by the natives that they render themselves immune by repeated small doses of the poison administered by lightly pricking the skin with scorpion stings. Metchnikoff found that the blood of the scorpion has strong antitoxic power against scorpion venom. Dr. Charles Todd, of the Department of Public Health of the Egyptian Government, has succeeded in making an antitoxin by immunizing horses against scorpion poison. The serum from the horses, in doses of 2 cubic centimeters, injected into the patient, is capable of neutralizing the poison of a scorpion. It possessed both preventive and curative power, and is now used in Egypt with 
the result of saving lives and reducing the pain of scorpion poisoning.

Hook-worm disease, uncinariasis, is due to a Hook-worm parasite which attaches itself to the inside of disease. the intestine and sucks the blood. It threatened to invalid the whole population of Porto Rico ten years ago. The recent studies of Stiles show that $\mathbf{1 2 . 6}$ per cent. of the employes in the cotton mills of the Southern United States are afflicted by the disease. Mr. John D. Rockefeller has given one million dollars to be employed by a commission towards the study and conquest of the disease in this region. It is now capable of control as a result of experimental methods. Fortunately a substance has been discovered which when taken internally causes the parasites to becomes dislodged, after which the only treatment necessary is that for the anemia.

Filarial disease is caused by a nematode Filarial worm of which there are over 200 species. disease. Some are parasites in dogs and birds. They find their way into the lymphatic and blood vessels of man, and are causes of many of the common diseases of warm countries. How these parasites entered the body was not known until the notable discovery of Meson (1879) of the 
Filaria nocturna in the mosquito. Bancroft, G. C. Low and S. P. James made the same discovery at about the same time. Grassi and Noè have more recently found the filaria taken up from dogs by the mosquito. Further studies have shown that the filaria has a cycle of development in the mosquito. Although no human being has been experimentally inoculated there are the strongest reasons to believe that this disease is transmitted in a manner similar to malaria. These parasites cause a plugging of the vessels and the production of many once obscure symptoms, one of the most striking of which is the enormous swelling called elephantiasis. Some of the hematobia have the power of penetrating mucous membranes, and entering the blood and lymph channels by their own motility.

Cancer.

If cancer is ever conquered it will be, most probably, as the result of animal experiment. Surgery has done about all it can. A large number of cases are cured by removal of the disease, which is at first local. If not removed, it spreads into the adjacent tissues, and later becomes disseminated through the body. Early recognition is now the important thing. If the disease is completely removed it is cured; but in 
a large percentage of cases it begins in the internal organs and when recognized is beyond eradication. Cancer is becoming more prevalent. In New York State 7000 people die annually of cancer. One in every twenty deaths is from this disease. In England the report of the Registrar-General shows that of women over the age of thirty-five, one out of every nine dies of cancer. Its manner of growth and its general pathology are well in hand. It has been zealously studied by Virchow, Cohnheim, Lebert, Waldeyer, His, Remak and many others. But its treatment has not kept pace with the treatment of the other diseases.

A new era in cancer research was opened by the discovery that the disease is prevalent in animals, and that it can be transplanted from one to another. This makes available the experimental method. The animals found to have cancer which can thus be experimented with are dogs, rats and mice. Hanan in Germany, Morean in France, Loeb in America, and Jensen in Denmark were the pioneers in this study (1901-1902). Thousands of these animals are now being observed by the exact methods of the laboratory. An immense amount of research concerning this disease is 
in progress all over the world. New York State supports a Cancer Research Laboratory at Buffalo, where Gaylord and his associates are doing admirable work. Similar laboratories are supported by government aid at Berlin, Frankfort, Moscow, and Paris. All the more active general pathological laboratories are engaged in the work. Important work is being carried on at Dundee and Manchester. The Great Middlesex Hospital in London has recently had given to it $£ 200,000$ for the promotion of cancer research. The London Cancer Hospital has received £100,000 for the same purpose. Splendid work is being done at the Imperial Cancer Research Laboratory in London, where Bashford is carrying on his studies. The Harvard Cancer Commission of Harvard University, is making notable contributions to the subject. During the past year, 1909, the late Mr. George Crocker, whose wife died of cancer and who himself died of the same disease, bequeathed $\$ 1,500,000$ to the College of Physicians and Surgeons in New York for cancer research.

The men thus occupied are working in cooperation, and by so doing are spared the 118 
necessity of repeating the experiments. It has been found that cancer can be cultivated best in rats and mice. The line of research now proving most hopeful is in the production of artificial immunity in infected animals. This has been accomplished. It now remains to apply these principles to man. As one observes what can be done with these animals in rendering them immune to cancer he can not but think that we are nearer the long sought secret than ever before, and that cancer is to take its place among the conquered diseases.

Although this line of research has been in progress only since 1902, brilliant results have been secured. It has been learned that cancer, unlike the infectious diseases, is extremely sensitive to constitutional conditions. Reinoculation increases the virulence of the growth. By vaccinating animals with certain slowly growing tumors an immunity has been secured even against the most virulent cancer. Immunity has also been produced by injecting the animals with extracts from certain normal organs. In dogs a number of cases have been cured by transfusing into the circulation the blood of dogs previously rendered immune. A number of the best trained scientists in the world are 
Experiments with drugs.

devoting their lives to this line of research. Many observers believe that the solution of the cancer problem is in sight.

All of the drugs which have a positive recognition and use have been placed upon a scientific basis by animal experimentation. Drugs need not now be used empirically but with a definite knowledge of just what they will do. The soporifics, the anesthetics, the antiseptics, the vaso-constrictors and vaso-dilators have all been accurately tested. These animal tests have resulted in the throwing out of many inert and useless drugs. Animals also lend themselves to the teaching of pharmacology, and to the determining of the strength of drugs. All reliable pharmaceutical houses employ animals for determining the efficiency and potency of their products. Drugs are not now estimated so much in grains and ounces as in actual potency to do certain things.

Sir James Y. Simpson first learned the action of chloroform by trying it on rabbits. The action of cocain was tested in the same way. Toynbee first tried prussic acid upon himself and was found dead in his laboratory. Now the properties of drugs are determined upon animals. 


\section{VIII}

\section{ANIMAL EXPERIMENTATION AND SURGERY}

During the past twenty-five years the ad- Surgery vance of surgery has been greater, perhaps, of animals than that of any other branch of science. If same as we look through all the catalog of surgical ills that of man. there is not a single one but has been mitigated by experiments upon living animals. To discuss this subject fully would mean to discuss the whole field of surgery. The lower animals are subject practically to all of the surgical ills. The healing of their tissues is according to the same vital processes as are observed in man. It would be strange-indeed, unnatural-if serious operations, which were to be attempted for the first time, should not be practised upon animals instead of upon men. Without animal experimentation all new surgical operations amount to vivisection upon man.

In the surgery of the nervous system, the ex- Nervous periments in brain localization have made it system. possible to know the seat of brain diseases be- 
cause the functions of the different parts of the brain have been worked out, and the location of disease is now determined by its interference with these functions. Tumors, hemorrhages, obscure compressing-bone-fragments, and foreign bodies can now be localized. Operations for the relief of these conditions are common occurrences, and are made possible and successful by virtue of these experiments. Such operations were utterly impossible before brain localization was studied upon animals. Not all brain tumors are amenable to surgical treatment. The disease untreated is fatal. Out of 440 reported cases treated by operation 186 have resulted successfully. This is still a high percentage of failures, but it represents $\mathbf{1 8 6}$ persons saved.

Blood

The surgery of the blood vessels has been vessels. aided by these means. Studies of the effects of ligatures upon blood vessels were practised on dogs; and every day, surgical patients are enjoying the benefits accruing therefrom. Prior to the year $\mathbf{1 7 8 5}$ the best known treatment for aneurism consisted in exposing the aneurism and tying the vessel in the wound. The operation was frequently unsuccessful owing to fatal secondary hemorrhage. John 
Hunter worked out the operation which was most successful for two hundred years; it consisted in tying the vessel in sound tissue some distance above the tumor; but before he attempted this upon the human subject he experimented with the operation upon dogs, and found how it could best be done. This operation has saved many lives and many limbs. Before this time 85 per cent. of people with aneurism of the main artery of the leg died of it; now because of Hunter's operation and the perfection of aseptic surgery through the studies of Lord Lister, less than 2 per cent. die. In more recent time Matas has improved this operation by sewing up the opening in the artery, and allowing the circulation to continue.

The operation of transplanting organs and Transstructures from one animal to another has atplantation tained a degree of perfection which points to of organs. its feasibility in man. It has already been applied in connection with some organs-the thyroid and the ovary-and promises to become a useful field of surgical endeavor. Kocher has transplanted bits of thyroid from one animal into the long bones of others. $\mathrm{He}$ has then been able totally to remove the normal thyroids from these latter animals with- 
out causing disturbance of their health. The most recent success in this line has been the transplantation of the whole joint-the two bone ends and the encapsulating ligamentsfrom man to man in cases of removal of joints by injury or disease. For many years the bones of animals have been employed to fill defects and gaps in human bones. Recently the whole knee joint has been taken from an amputated leg and introduced in the place of a knee joint which had become destroyed by disease.

The work of Carrel in transplanting whole organs, such as the kidney, from one animal to another, is of prodigious importance to the advancement of surgery. It has attracted the attention and admiration of the scientific world.

Intestinal surgery.

Among the procedures which have been made possible by the art of surgery is the sewing of wounds of the intestine. These injuries were once associated with a high degree of mortality. Intestinal surgery has reached a point of perfection in which the most extensive damage to the bowel can be repaired. More than ten feet of intestine have been removed and the two ends of the bowel tube successfully united. The excision of areas of irreparably 
damaged bowel is now a common occurrence in every surgical hospital, and the sewing of wounds of the intestines is saving hundreds of lives each year. These operations have all been practised upon dogs, the animals being under the influence of anesthesia and surrounded by all the precautions essential for their recovery. It is to be regretted that animal experimentation is so difficult and uncommon that most surgeons gain their first experience in sewing wounds of the intestines when they encounter the necessity for the operation in the human abdomen.

The study of the regeneration of bone from Surgery the periosteum was carried on by Du Hamel of bones. (1740) and Hunter (1772) upon pigeons, chickens, and guinea pigs. Sym (1837) continued these investigations upon dogs and found that if a part of a bone and its periosteum were taken away the bone did not grow together and the limb was useless, but if the same length of bone were removed and its periosteum left, new bone would be reproduced. Ollier (1858) practised resection of long bones in dogs and rabbits. As a result of these experiments when bone now has to be removed because of disease or injury it is stripped out 
Other operations.

of its periosteum, new bone forms, and a useful limb is secured, whereas formerly thousands of limbs were amputated or left useless by these conditions.

Orthopedic surgery owes much advancement to such experiments. Hunter first performed tenotomy upon an ass. Skin grafting and the transplanting of skin was practised on animals.

The newer anesthetics have all had their character determined upon animals before man was subjected to the hazard of their employment. The surgery of the kidney has been especially advanced by this branch of work. Billroth had a patient with a cancer of the larynx. The removal of the larynx was the only means of saving the man's life. The operation had never been done. Czerny, his assistant, removed the larynx of dogs, and found how it could best be performed. Then they proceeded with the patient, and saved his life.

Before the Royal Commission on Vivisection, Sir H. R. Swenzy demonstrated conclusively the great advancement in the treatment of diseases of the eye that has been made by experiments upon animals.

Tetanus.

One of the most frightful surgical diseases with which we have to contend is lockjaw. It 126 
occurs in man and animals, chiefly the horse. The cause of the disease was discovered by $\mathrm{Ni}$ collaier to be the tetanus bacillus. The same organism is identified in both man and animals. The organism is found in the soil generally; and wounds becoming infected with earth are particularly prone to develop tetanus. The tetanus bacillus having been discovered, Behring and Kitasato, by animal experimentation, perfected an antitoxin which renders man and animals immune. No antitoxin has yet been evolved that will cure this disease. If it is suspected that an individual has received tetanus infection, and the antitoxin is used, the disease does not develop; but in cases in which tetanus has developed the antitoxin has but little effect. The disease has such a high mortality and the sources of infection are so well understood that it is much employed as a prophylactic in possible infection. Tetanus does not develop until one, two, or three weeks or more after the tetanus baccillus has gained entrance to the body through the wound. One of the wounds most commonly followed by lockjaw is the blank cartridge wound of the hand common on the glorious Fourth of July. The death rate from these wounds is appalling. 
An active campaign has been conducted throughout the medical profession to reduce this mortality. All over the country, surgeons and medical journals have advised the injection of tetanus antitoxin in every case of blank cartridge wound. The American Medical Association has compiled statistics of Fourth of July fatalities for the past six years. Six years ago the Fourth of July tetanus cases numbered 416. Then physicians began a more general use of antitoxin in all cases of blank cartridge and cannon cracker wounds. As a result of this campaign of prophylaxis, by antitoxin injections, from $4 \mathbf{1 6}$ cases of tetanus in 1903, the number dropped to 105 cases in 1904, 104 cases in 1905, 89 cases in 1906, 73 cases in 1907 , and 55 cases in 1908 . This reduction in the number of tetanus cases took place while the number of accidents remained practically the same each year, and while the number of deaths from causes other than tetanus was steadily rising from 60 in 1903 to 108 in 1908. It is thus evident that the saving of at least 300 lives from tetanus has been accomplished each year through the prophylactic use of tetanus antitoxin, in the cases of Fourth of July wounds alone. These represent but a small 128 
portion of the wounds through the whole year in which it is used. For immunization, the antitoxin now employed seems infallible, tetanus never occurring in a patient receiving it.

Many surgical operations are essentially experimental. In the absence of positive knowledge of obscure internal conditions, the surgeon exposes the seat of the supposed disease. ('These are called "exploratory operations," and represent what surgeons know to be a large class.) Much abdominal surgery is even yet experimental. For example, in cancer of the stomach, if the disease has developed far enough for a positive diagnosis to be made, it has gone too far to be curable. It is in the early stage, when its symptoms are but slight and obscure, that a curative operation can be done. Practically all operations for this disease which are curative are exploratory operations, prompted by but a suspicion that the disease may be found.*

*If the disease is not found, no harm is done; if it is found, a life may be saved. One of the reproaches to medicine is that almost invariably the disease is found to exist when exploratory operation is done for it. That means that in most cases there has been a strong suspicion of cancer to have prompted operation, and in the present state of knowledge there can not be a strong suspicion unless the disease is mell advanced. It would be more to the credit of medicine if more cases should be operated upon when the signs are so slight that exploration

Operations essentially experimental. 
Much of the surgery of the abdomen has been developed by operations upon man which must properly be called experimental. The surgery of ulcers of the stomach and duodenum; perforating typhoid ulcers; intestinal obstruction from hernias, adhesions, volvulus, and intussusception; peritonitis; appendicitis; obstructions of the gall ducts; and many other conditions peculiar to man have had to have their treatment worked out in the human abdomen. The fact that the mortality from all of these diseases is being enormously reduced as time goes on should cause the regret that those early patients had to be sacrificed to the gaining of experience; but all perfection in technic is worked out through painstaking elimination

It means much to human life in the working of error and development of minutia.

out of this perfection, that wherever the dead body of man or the living lower animal can be used for investigation these two sources of information have been called upon. But even yet there is too little of the post mortem examination and too little animal experimentation

occasionally discloses no disease. Operation should be done upon the suspicion of the disease, with the view of making a diagnosis either of cancer or of no cancer: if the first condition is found, operation offers much hope; if the latter condition is found, so much the better. 
employed towards the end of the conquest of disease.

In the development of all of this experience in the thousands of surgical operations which are being performed every day, there is going on a constant exchange of opinions and reports of methods and results through the medium of societies, congresses and publications, which give every individual worker much of the benefit of the experiences of others. There are no secrets in the world of scientific medicine. 


\section{IX}

ANIMAL EXPERIMENTATION AND DISEASES OF THE LOWER ANIMAIS

Experimental methods essential.

Trichinæ.
Animals as well as man reap the benefit of animal experiment. The great problems of animal industry can not be solved by statistics and calculations from the easy chair. The infectious and epizootic diseases continued their ravages until their causes and natures were discovered by scientific experimentation. We have seen what has been done with anthrax, malignant edema, hog cholera, chicken cholera, silk-worm disease, hydrophobia, and bubonic plague. Contagious pleuro-pneumonia, Texas fever and foot-and-mouth disease also have been brought under subjection.

The trichinæ problem in the United States, dealing with a small worm that attacks pork, which for many years involved an annual loss to trade of fifty million dollars, has been worked out by the investigations of the Department of Agriculture, and means for over132 
coming trichinosis are now fairly well in hand. Fifty millions will buy a good many shoes and stockings for farmers' children. While this work was in progress a bill was actually introduced in Congress, and defended by able and well-meaning people, which was aimed to stop these experiments; but it permitted any butcher to feed trichinous meat or offal to dogs, cats, pigs, rats, or any other animals, causing trichinosis in them, and so long as it was not done as an experiment he would be violating no law. Trichinosis in man was never recognized as the same disease as that which occurs in pigs until 1860 when some of the parasites taken from a patient who had died of the disease were fed to rabbits. In these animals were found the same type of trichinæ as were found in the pork which the patient had eaten. These cases had never before been understood but now the matter is cleared up.

When the Bureau of Animal Industry was Texas created in the United States in 1884, the cattle fever. industry in this country suffered heavy annual losses from a disease called Texas fever. The disease appeared among cattle in the herds, in the stock yards, in cars and ships on the way to market, and death occurred in 50 per cent. to 
90 per cent. of cases. Sometimes 150 cows would die on a ship from this disease. Not only was the loss of cattle heavy but the reputation of American cattle in foreign markets was damaged. The disease was unmanageable because its nature was not understood. The way the investigators went after this plague, and the problems which they solved reflects much glory upon the scientific spirit of this country. Briefly, they pursued the methods of Pasteur in his researches in diseases of animals. They identified the cause of the disease as a microscopic parasite in a certain cattle tick. They experimented with these ticks upon healthy animals. They hatched the ticks in the laboratory and placed them upon northern cattle and produced the disease. Then methods for identifying and destroying the dangerous ticks were perfected. Finally northern cattle, to be taken south for breeding purposes, are inoculated with the blood of southern cattle and given a mild attack of the disease which renders them immune for the rest of their lives. These experiments have reduced the loss from Texas fever among such animals from 90 per cent. to 10 per cent. Researches are now under way with the aim of finding a means of destroy- 
ing the ticks of southern cattle. If this can be accomplished the last difficulty will be overcome.

Contagious pleuro-pneumonia was at one Pleurotime one of the most fatal scourges of cattle. By the experimental inoculation of cows the contagious nature of the disease was discovered. This was done while the disease was prevalent in the Eastern states; but with this knowledge gained it was possible to prevent its spread to the great cattle ranges of the West. A similar study of foot-and-mouth disease has resulted in diminishing its prevalence, and preventing its transmission to man.

Vaccination for the prevention of black-leg among cattle has practically eliminated the disease. Before this treatment was begun the mortality among herds afflicted was 10 to 25 per cent. each year. The loss of young cattle in the United States was 100,000 head yearly. In the first year succeeding the introduction of vaccination for this disease the loss was reduced to 0.6 per cent., a saving of 94,000 head of cattle, worth about two million dollars. To accomplish this, fresh animals which had died of the disease had to be secured to make the vaccine; occasionally a calf had to be infected ar-

Foot-andmouth disease.

Black-leg. 
tificially for this purpose and the strength of each lot of vaccine had to be tested by inoculating guinea pigs. Yet while these experiments were being made a bill was strongly supported in Congress making it compulsory to give the animals an anesthetic while the experiments were in progress - that meant to keep the animals under the influence of ether from periods varying from two days to two weeks-an absurd and impossible thing.

Tuberculosis.

Tuberculosis is one of the most prevalent diseases among animals under domestication. Among cows it is especially important because of man's dependence upon them. In all of the great veterinary laboratories studies of this disease among animals are being carried on with the view of finding means to render animals immune or to cure them. For example, Vallée reported at the International Veterinary Congress, at The Hague, in September, 1909, the results of some of his experiments upon cattle extending over a period of six years. He had used 166 grown cattle and 500 calves. His best results were secured by intravenous inoculation with living tubercle bacilli of an attenuated strain which were derived from the horse. He regards the low virulence 136 
of the organisms as the important factor. Inoculations with killed bacilli did not produce results; inoculations with vigorous tubercle bacilli, of course, would cause tuberculosis in the inoculated animal. The complete absorption of the organisms was also found to be an important factor. Administration of the bacteria by mouth conferred only a temporary immunity, the younger the animal the better the immunity. Vaccination by mouth permitted young cattle to resist for one and two years fatal infection when they were stalled in close contact with cows with advanced lung tuberculosis, while the control cattle, not thus vaccinated, rapidly contracted the disease. There is every reason to believe that the methods now being worked out to control tuberculosis in animals will be applicable to man.

It is not the launching of dreadnoughts, the rise and fall of cabinets, political intrigues, or the foot-ball game that are of the greatest importance to mankind, but such work as this, carried on without ostentation, with infinite patience, by earnest and devoted men, whose best reward is the assurance of their own hearts that they have done well. It is such as these who are to redeem the world, not they who 


\section{THE CONQUEST OF DISEASE}

Glanders.

bring the sword and the cry of hell and damnation.

Glanders or malleus was a few years ago one of the most common and fatal of the diseases of the horse. It was formerly regarded as noncontagious, and animals thus affected were sold to truckmen, farmers, and street railroads, and disseminated the malady. The disease is inoculable to man; and when we look into the older text-books on surgery we find how much attention it required. Now but little space is given to it, and there are few surgeons of the younger generation who have ever seen a case of glanders in man. In 1837 the French surgeon Rayer was struck by the resemblance of a disease called putrid fever, occurring in man, and glanders of the horse; and since this disease was usually observed in grooms and stable men, he undertook to prove or disprove its identity. He inoculated a horse with the discharges taken from a sore on a patient having putrid fever; and the animal developed glanders. With this beginning he proceeded to prove the communicability of the disease from one animal to another. The story is a long one. Knowledge when once obtained seems simple enough, but wringing from na138 
ture new facts is one of the rarest and most difficult tasks that man sets his hand to. The nature of the disease has been discovered. It is due to the bacillus of malleus. It is now prevented. A serum for its early diagnosis has been perfected; it is now possible to recognize the disease early and isolate or destroy the infected animal; and glanders is becoming an uncommon disease. But this knowledge has been gained at a great cost. The baccillus of malleus has caused the death of a number of investigators working with it. A single bacteriologist at the University of Chicago knows of six cases among laboratory workers, all of which proved fatal. The experimental biologist exposes himself to the disease in order that other men may be less exposed to it.

Influenza, occurring among horses, is controlled by an antitoxin; so is rinderpest, a tropOther diseases. ical disease of cattle. The early diagnosis of tuberculosis in cattle is possible only by means of the tuberculous product used for that purpose. It is worthy of note that diseases of animals also attack men, notably tuberculosis, anthrax, malignant edema, trichinosis, foot-andmouth disease, hydrophobia, bubonic plague,

${ }^{1}$ Journal American Medical Association. Vol. 50. No. 20. 1908. 139 
Human

therapy

and animal therapy.

glanders, and tetanus. The animal industry in the United States produces exports of over two hundred and fifty million dollars. There is invested in live stock, exclusive of poultry, in this country a capital of four billion dollars. From a commercial standpoint this itself is well worth protecting.

The progress in the making of antitoxins and immunizing sera for the treatment and prevention of infectious diseases in animals has advanced much further than for the diseases of man. This is because experiments for the benefit of animals have been carried on with animals of the same families and species; but for the benefit of man, animals of other species have had to be used. When an antitoxin for a disease of the horse is made the horse is used in its preparation; when an antitoxin for a disease in man is required we have to use the horse or some other animal. And it is a well known fact in experimental physiology that the living tissues and fluids of animals are poorly interchangeable from one species to another. That is the reason why at this early period in the history of serum therapy the cure of infective diseases in animals has advanced farther than the cure of the infective diseases in man. 
I am opposed to capital punishment, but were I a condemned criminal, destined to execution, and were $I$ a believer in a loving God who would be influenced in His future disposition of me by my conduct between the hour of my condemnation and death, and were I a believer in His infinite mercy and love for His children, I should feel that the best use to which I could give my life, in order to secure His approval, would be in the interest of my fellow men, just as the dumb horse is now made to give his life for the relief of human suffering; and I should feel that such a service would meet with more approval in His eyes than the mumbling of flattering expressions in $\mathrm{His}$ praise or repeated acknowledgment of my own sinful weaknesses; and, whether I believed these things or not, I should feel that, had I really sinned against mankind, I would expiate that sin more fully and end my days more happily by offering my life to human service, in practical or experimental medicine than $\mathbf{I}$ could by serving simply to demonstrate nothing more important than the effects of the electric current or the hangman's noose.

There is still another side to this question of animal experimentation which may be touched 
Animals transmit diseases.

upon; that is, that, the farther these studies upon the lower animals are carried, the more closely are their diseases found to be allied to those of man. We have seen that tuberculosis and a number of other maladies are interchangeable between men and animals, and that this is particularly the case with animals under domestication. Some of the recent literature of this subject deals with domestic animals as carriers of human diseases. The Académie de Médecine, Paris, passed a resolution in 1908 urging instruction of the public in the dangers of infections from dogs and cats. ${ }^{1}$ Since the discovery of the cause of diphtheria it has been found that cats are carriers of this disease, and outbreaks of diphtheria have been traced to the family cat. This animal is also a purveyor of whooping-cough and broncho-pneumonia. The $\mathrm{dog}$ is the most common carrier of the intestinal parasites. The echinococcus disease, giving rise to cysts and abscesses of the liver, is contracted from the dog and is particularly common in Iceland where the dog is an intimate member of the family, and in this country among the people who live in close social relation with the dog. Tape worms and other

${ }^{1}$ Bulletin de l'Académie de Médecine, Paris, 82, No. 40, 1908. 142 
intestinal worms are essentially diseases of dogs, and are transmitted by dogs to man. One of these parasites common among children who play with dogs and cats has been identified as developing its larvæ in the fleas which infest these animals. The studies of Koch and Rabinowitch show tuberculosis to be present in more than 25 per cent. of birds in cages under domestication.

Since Pasteur revealed to us the world of the "infinitely small" we have learned that our hands are rarely very clean and that the materials which gain access to our gastro-intestinal tracts are of so much importance that we are becoming irreligious enough to give some thought to what enters our mouths. While to the naked eye the fur of our domestic animals may look clean, these animals are notoriously dirty in their bodies and in their habits. A profitable study could be made by those who harbor these animals as a part of their households, as much information has been accumulated upon this subject. Regarding the dog as a public menace, the city of New York in one The dog, a menace. month last year caused 6000 to be killed. London kills by suffocation more than 30,000 dogs annually. Boston kills 3500 dogs and 14,000 
cats annually. It is necessary that such measures be adopted or the cities would become overrun with ownerless dogs. Out of $\mathbf{7 0 0 0}$ stray dogs captured by the Board of Health in New York in one month, only 2 per cent. were claimed or wanted by any one. The rest were left in the hands of the authorities to be disposed of. It is just such stray animals as these that are used to increase biological knowledge and help humanity. Which is the better way for them to die, in contributing to man's relief from the scourge of disease or in having their lives ignominiously ended by being suffocated in closed chambers filled with carbonic acid gas? 


\section{$\mathbf{X}$ \\ CONCLUSIONS}

One of the great mistakes of our time is the general promulgation of the idea that most everything is known. It prompts students to go to the books and to consult authorities, when instead they would do more wisely to go to nature for the facts. The notions concerning our great wisdom spring from the comparison of today with the past. Comparatively much is known. But an infinite amount remains yet to be learned! When future wisdom looks back upon us, it shall see us groping and struggling for the great truths hidden in the world of nature about us; and in the light of what is yet to come we shall seem ignorant and benighted.

Science must go on and on, seeking for more. It is the lack of knowledge that makes the world unhappy, not the converse. In the pursuit of knowledge concerning the human 
race, the lower creatures are lending their help. Let science go on with its holy mission of helpfulness. If it has not kindness, it is not science.

There should be no misconception of the meaning of animal experimentation. Let it be remembered that it does not mean animal cruelty. The experiments in which painful operations without anesthesia are practiced are comparatively few. These are experiments upon the nervous system in which anesthesia would nullify the results, just as operations sometimes have to be done upon man without anesthesia. Such experiments are made by men who go about their task with every humane consideration for the animals under observation. There have been experiments that could be denominated as cruel. That such things have occurred is due to the defects of human judgment which are found in all professions, and which are keenly regretted by students of the biologic sciences. I offer no defense for cruelty to animals. But to talk of the "cutting up" of living animals, popularly spoken of by those unfortunate persons who speak in ignorance of these things, is as absurd as it is malicious. 
The object of these studies is to benefit humanity. The men who add to this beneficent knowledge have that as their object. None but persons engaged in philanthropic work can understand the impulses lying at the base of such pursuits. The world's great scientists have all found their best rewards in having accomplished that one thing. No knowledge is useless. Every one who wrests from nature one of her secrets is a benefactor, irrespective of whether he sees an immediate practical application of his knowledge or not. Some day it will fit in with somebody else's discovery and be applied. Most of the great discoveries have been made of service in this way: they represent the fitting together of several facts which singly were of little avail.

Nor do I wish to imply that progress in the biological sciences could not continue without these studies of living animals. Nothing can stop the acquisition of knowledge. But all wellbalanced, well-informed men are agreed that they have been of greater help in practical medicine and hygiene than any other agencies. So valuable in promoting human health and conserving human life have these studies been that it cannot be regarded as merely the privi- 
lege of science to carry them on, it must be regarded as its duty.

The importance of this subject should prompt some consideration of those deluded persons who oppose these investigations. Most are victims of ignorance. Others are not. The psychology of their opposition is well understood by students of sociology and of neurology. There is no great work for human betterment but has its "anti" movement. The business interest also involved in this opposition testifies to the possibilities of inhumanity to man as a business enterprise.

Those who call themselves "antivivisectionists" employ the term "vivisection" to designate animal experimentation. These persons employ exaggerated statements, perversions of facts, and misinterpretations of the object and methods of scientific work to becloud this important subject. As an example, one of these persons, recently published the statement that, the physiologists demonstrating to their classes, "cut out the eyes of living rabbits in order to demonstrate their internal structure"! But there are methods of misrepresentation besides actual falsehoods. Some of the crude methods of experimentation practiced many years ago, 
and now long since obsolete, are cited to harrow up the sentimental, as though they were still in use. A disposition to deny the well recognized scientific importance of animal experiments is also displayed by taking a supercilious attitude of incredulity towards scientific work. Such methods do not detract from the importance of scientific study, but they have influenced the uninformed and the neurotic to an attitude of hostility towards it. By appeals to the emotions of these classes it is always possible to awaken the old superstitious spirit of antagonism and misunderstanding of science, with which human progress continually has had to contend. They exalt their own undisciplined emotions above the agonies of mankind.*

*An "antivivisection exhibit", is at present on view to the public for two weeks at a busy point in the shopping district in New York City. This is a traveling exhibit professedly to "educate" the public regarding the "horrors" of animal experimentation. The chief objects exhibited are stuffed dogs confined to animal holders. These things are put in the front window to attract the crowd. The dogs are of the type of lap dogs and other pets, fastened in distressing positions. Visitors are told that this is the way dogs are fastened in laboratories, but anesthesia is not mentioned. An attendant explains that a certain part of the holder is for the purpose of " breaking the jaws of the dogs." An oven contains a stuffed cat in an aspect of great suffering. This, an attendant informs the visitors, is an apparatus used in laboratories to roast animals alive "in order to study their nerre action and circulation!" The oven probably was secured from a laboratory; it is an ordinary laboratory incinerator which is used to burn 


\section{This human weakness is responsible for put- ting in the way of animal experimentation obstacles which have been of decided hindrance to scientific advancement. Ignorance, super-}

infected refuse and waste material! One of the travesties of this exhibition is the misrepresenting pictures, drawn from the cruel imagination of morbid artists. There is a collection of these which are maliciously false. There are plates from scientific books showing dissections, but labelled with false legends such as, "This agonizing and hideous mutilation is performed without anesthetics."

Concerning this exhibition, the Journal of the American Medical Association, Dec. 18, 1909, makes the following comments:

"Such is the travesty on medical research presented to the public by the antivivisectionists. The untruth of the details has been stated, but the wickedly suggestive implicatons which make the very atmosphere of the display cannot be adequately described. The fundamental evil of the exhibition is the presentation of a false alternative. The picture of a dog bringing succor, and of another dog bound to a holder, entitled, 'The Way They Treat Us' and 'The Way We Treat Them', sums up the situation. If that were all, nobody would hesitate on which side to stand. It is no wonder that nearly fifty portraits of poets, novelists, statesmen, artists and clergymen, whose words express their objections to cruelty, have been collected to adorn the walls of this exhibition. Every decent man is opposed to eruelty. But that is not the question. It would be as fair to set up a picture of Grenfell stabbing his faithful dogs to death, labelled 'Is This the Way to Treat Your Pets,' as it is to represent medical research as this grotesque show represents it. Grenfell killed his dogs to save his life, and every man with common sense commends his bravery, resourcefulness and proper sense of values.

" The high purpose of medical research and its beneficent results for human welfare-the compelling motives of that investigation which utilizes animals, and the care taken for the comfort and health of the animals, in laboratories-these conditions, which alone give meaning and possibility to medical investigation, are kept carefully in the dark.

' The visitors at the exhibition are mainly women, though many children, some quite young, have been seen gazing at the horrifying sights. The attendants are women-women who have never seen the inside of a laboratory of medical research, 
stition, misunderstanding, jealousy, and selfexploitation have all contributed their harmful influences. This peculiar mental state has in many instances not been satisfied with the

and who let their morbid imaginings take the place of facts. They move about among the visitors making insinuating remarks and stating falsehoods with an easy assumption of knowledge they have never possessed. They show an instrument maker's catalogue to prove the truth of their representations-again with no mention of anesthetics. A catalogue of the instruments used in surgical operations on man could be used with the same sly suggestion of torture. As the visitors leave, the attendants hand them circulars containing garbled statements, misleading quotations, and reiterated falsehoods, the untruth of which has been often pointed out. Thus the exhibition is untrue in its representations, evil in its implications, and altogether harmful in its possible effects.

"When the exhibition was at Atlantic City last summer the Philadelphia Ledger was moved to state editorially: 'It is really a serious concern that a number of good women, or others, should devote their labors to harrying the nerves of the crowd and inciting them to ignorant hostility against the humane studies which have done so much for the services of mankind. The public exhibition of an anatomic museum would be in any case an offense against taste and decorum; when it is employed for misrepresentation and obscurantism and for the propagation of false sentiment, prejudice and intolerance, it is proper to speak of it only with the most serious condemnation. " "Utterly preposterous as the "chamber of horrors" on the Boardwalk must appear to all who know anything of the subject it pretends to illustrate, it yet has its serious aspect, as an attempt to play on ignorant emotion and to create a false sentiment in support of an unscientific, unreasonable, inhumane effort to impose indiscriminating and injurious restrictions on the acquisition of knowledge that is for the advantage of all living creatures.'

"When a lay paper takes such a stand as that, it is high time that members of the medical profession awaken to the harm that the opponents of research are doing. The public is being educated, but the ignorant are being led by the ignorant. If medical investigation is not to be seriously hampered in this country, those who do not know must be led by those who do, and must be taught to see the importance to the general 
ordinary laws which provide punishment for the infliction upon animals of "unjustifiable physical pain, suffering, or death;" but has striven to have enacted class legislation, putting scientific workers under special surveillance and restrictions, and allowing farmers, drivers, butchers and animal trainers to come under the general law. One of the most striking absurdities to which the spirit of unenlightenment has driven legislators has been this special legislation, hampering the work of educated men who are devoted to the relief of human suffering.

Such legislation often requires that an anesthetic shall be given to every animal experimented upon. One law made it necessary to give, an anesthetic to an oyster. In most instances the anesthetic would do the animal more harm than the experiment. On the other hand the physician has no restrictions imposed by law as to whether he shall give an anesthetic to a human being or not. Under the ordinary criminal laws the unjustifiable withholding of anesthetics from animals is a punishable of-

welfare of the efforts which are being made in the medical laboratories, with the help of lower animals, to penetrate the mysteries of disease and death that confront mankind on every side." 
fense. As to making a distinction between useful and unnecessary experiments any one who is familiar with the development of scientific knowledge knows the futility of such distinction. None knows what knowledge may become useful tomorrow. The demonstration also of facts which have been proven is essential for the training both of the student and the expert.

To place such experiments under the inspection of hostile or unenlightened inspectors has been of no service to man or animal. In England where animal experiments are inspected no good has come from it; but much harm has. The inspections have been matters of unneces'sary expense; the experimenters' attitude towards the animals has not been changed, and incriminations have continuously been aimed against the inspectors by the "antivivisectionists" because they have not reported finding cruelties. The inspectors have had no cruelties to report, and the sentimental yearners for revelations of horrible atrocities have accused the inspectors of having been corrupted by the experimenters. The compulsory reporting of experiments results in promulgating the results of work before it is completed; and every 
scientific worker knows the harm and danger of such prematurity. In some enlightened communities in which it has been impossible for these opponents of scientific investigation to have prohibitive laws enacted, they attempt to have passed laws which purport to "regulate" animal experiments, but which are to act as entering wedges for prohibitive and hampering laws.

The community, represented in the state, if it were wise would not only not place restrictions in the way of the men who are making the scientific investigations, but it would render them every possible aid. It is public shortsightedness not to give help to the work that has for its object the relief of human suffering, the lengthening of life, and the promotion of physical efficiency. Physicians and biologists who are engaged in such work are human and have the failings and limitations of all men, but they represent a class which in its feeling of moral obligation to both men and animals embodies the highest human attributes. It is inconceivable that men who in their treatment of human beings and in their families are gentle and considerate could countenance unkindness to animals. 
On the other hand, we may ask, what are the efforts of the "antivivisectionists" doing for humanity? Has a human life been saved or made more sweet by their activities? If their fullest desires were attained, not only man but animals, too, would suffer.

The methods employed by these misguided people are illustrated by the case of the woman who entered the University College, London, ostensibly as a student. After witnessing some experiments, she discontinued her attendance, and issued a book against animal experimentation, in which was displayed an utter failure of understanding of what she had seen. This was not so bad as the fact that the book contained misrepresentations. A Mr. Coleridge, the high priest of the British movement against animal research, made statements concerning the physiologist, Bayliss, relying upon this woman's tales for his facts. An action was brought against the man by Dr. Bayliss, who proved that the statements were false, and secured judgment for $£ 2000$ and costs-in all, nearly $£ 5000$. The money was turned over for the promotion of animal experimentation. The publishers of the book withdrew it from the market because of 
its false statements. This discredited woman at the time these lines are being written is appearing in America, repeating her falsehoods from the public platform.*

\section{During the summer months when the De- partment of Health of New York City was}

${ }^{*}$ A more recent illustration may be cited:-A New York daily paper has published for the "Antivivisection Society", a series of reports of "cruelties", to animals purporting to have come from employes of the Rockefeller Institute of Medical Research. Several whole pages have been spread with matter of this sort, which is based upon the statements of three ex-employes of the Institute, consisting of a woman who had been employed as a cleaner and helper, and two men who had been dismissed for inefficiency. These people, in the hands of the "Antivivisection Society," made statements which were a combination of falsehoods and truths with false coloring, all of which when edited by the propagandists of " antivivisection" produced a tale well qualified to harrow the undiscerning.

The sociologic importance of this matter does not lie in the fact that these ignorant and plastic persons have been led into producing false statements, but rather in the fact that an organized effort is made by well intending women to hamper this beneficient work, and that a newspaper can be found so ready to pervert the truth and inflict harm upon society.

Concerning this subject, the New York Times, (Dec. 28, 1909,) says:- "The Herald, continuing its mysterious efforts to bring medical science into public disrepute-efforts which, so far as they may be successful, can only make more numerous the dupes of charlatans and the mystical cults-devoted a page of its space yesterday to a description of animal experimentation in the Rockefeller Institute as seen by a woman whose right to speak with authority on the subject she proves by saying in her affidavit: 'I went there Oct. 21, 1908, cleaning in the afternoons.' And it is upon criticism from this person that the antivivisectionists and their journalistic supporters expect us to base the belief that Dr. Flexner and his carefully chosen associates are guilty, not only of atrocious cruelty in their work, but of performing it in a way so slovenly and 


\section{destroying the unclaimed, stray dogs, as all civilized cities must, a "Society for the Pre- vention of Cruelty to Animals" protested against it, but it had no solution of the problem to offer. Its only solution was to leave the dogs at large.*}

unskillful, in such complete violation of all the principles of modern aseptic surgery, that the attainment by them of any kind or degree of success would be quite out of the question.

" As it happens, however, men have already won worldwide recognition for their repeated achievements in both preventative and curative medicine, and their triumphs are acclaimed by their professional brethren as those naturally to be expected when experts of the highest rank have been enabled to pursue their studies with the best of facilities and in the best of conditions. The story told by the woman who 'went there cleaning in the afternoons' is, indeed, sufficiently horrifying, for those who can accept it as true, but in its essential features it is much such a story as might be told by an equally ignorant and sentimental observer who watched what goes on daily in the operating theatre of any big hospitalwith men, women, and children substituted for dogs and eats to make the tale of torture and mutilation the more dreadful. In the hospitals as in the Rockefeller Institute, the use of knives and saws on living tissue is a frightful spectacle if viewed out of relation to purpose and consequence. But in both cases, when viewed in that relation, the cutting, and even the moans of fright or pain, take on an entirely different aspect. One sees no longer a revival of the mediæval torture chamber, but the application of beneficient knowledge as it guides practiced hands in the alleviation of suffering and the conquering of disease.

"The testimony of this new witness may not be intentionally false, but false much of it certainly and obviously is, and its similarity to that given, and conclusively refuted, in England concerning the famous brown dog, will instantly strike anybody familiar with the details of the case which resulted so disastrously for Mr. Coleridge and Miss Lind-ap-Hageby.',

*At the same time, the official in charge of clearing the streets of these stray animals, received a letter threatening him with death if the killing by the city of unmuzzled and unleashed dogs was not immediately discontinued. 
The neurologists have studied and described a disease condition, which has been designated by the name, zoöphilic psychosis, in which there is an inordinate and exaggerated sympathy for the lower animals often associated with delusions that they are persecuted by man. It has not exactly the qualities of an insanity, but it is distinctly a psychasthenia or obsessive psychosis. Curiously these cases display a sympathy for suffering in animals while they show decidedly less concern for human suffering. They have a peculiar lack of proportion. This is no unusual condition. Dana, Raymond and Janet have reported some striking cases. Morel reports the case of a patient who would faint at the sight of a sick animal but who did not fail to rent his windows on the days of executions, and allow his servants to go and witness the executions. The cases observed in America have been in persons who were found in the ranks of "antivivisectionists" and kindred cults. Dana describes them as cases of fine feelings gone wrong, sometimes involuntarily, as the result of an overgrown sentimentality, and sometimes as the result of habit selfishly nursed into an unmoral mode of life.

${ }^{1}$ Medical Record, March 6, 1909. 
Their sympathies go out to those animals which are petted and caressed; but they are not disposed to be interested for the animals which are truly abused-the live stock exposed to the butcher and the market, with their thirst and their hunger and their wounds. Unfortunately for the steers, calves, sheep, and hogs, they are not fondled by the victims of zoöphilic psychosis. Besides these mentally diseased types and the mentally oblique, there is a large class of good-natured persons who are influenced by the earnestness of the others and whose opposition to animal experimentation is made possible because of their ignorance of its meaning.

"Antivivisectionists" interest themselves not so much in experiments upon fishes, insects, pigeons, rats, mice and snakes, nor in cruelties to men, cattle, chickens and sheep. Their interests are bent towards those useless animals which can be made the objects of fondling and which compared with the other animals play a minor rôle in the great field of scientific experimentations. The neurotic qualities of their activities is displayed in this bias of interest.

In the United States are 100,000 orphans 
and destitute children, inmates of institutions, all of whom are suffering for want of the two great essentials-home and love. Look at their listless faces; they tell the story of their starvation for these two needs of the growing child. Let us take a single city, New York. It had 14,000 homeless children in 1908; and in that year issued 44,000 dog licenses. It is estimated by Richard Barry that there are at least 5000 dogs in New York having elaborate outfits (dress collars, expensive blankets, beds, trouserettes, etc.), and living in perfumed luxury. There are seven shops on two streets in that city devoted exclusively to fashionable dogs' furnishings, selling everything for these animals, from silk-lined blankets and foot warmers to canine manicure sets, automobile outfits and mahogany dressing tables. The average cost of keeping each of these fashionable dogs is about $\$ 260.00$ per year. One woman spent $\$ 17,500.00$ in a year upon her pet poodle, its luxuries including a French maid in exclusive attendance. These dogs eat the expensive delicacies of the market.*

\footnotetext{
* For a further discussion of this subject the reader is referred to a striking article by Richard Barry, on "Dogs and Babies," in Pearson's Magazine, December, 1909, from which this information is taken.
} 
No one would be so cruel to a child as to desire that the place of the dog in the luxurious home of its rich mistress should be given to one of these homeless and unloved babes. It is better that the dumb animal should be the victim of the perverted instincts of these women than that a human being should. But it is noteworthy that the money that women are lavishing upon their dogs in the United States would be sufficient to take every one of these 100,000 children out of institutions and put them in real homes, just as is done in countries which are sufficiently civilized not to practice the herding of children in institutions. A German scientist has divided women into two classes-the mother-type and the prostitutetype. Women displaying a fondness for fondling dogs, he explicitly explains, do not belong to the mother-type.

The world has none too much affection. The human heart craves it, and is sweetened by it. I begrudge for every unloved man and woman and for every unmothered child the caresses that are bestowed upon cats and dogs. All of these animals in the world combined have not the sense of appreciation or joy in a kindly and loving caress that is capable of well- 
ing up in the heart of a single one of the most lowly urchins of the street.

Concerning animal cruelty, the real cruelty to animals is not in the hands of those who are making animal studies to help their fellow men. All of these experiments upon vertebrate animals of every character with or without anesthesia everywhere in the world, are inconsiderable are infinitesimal, compared with the atrocious cruelties of the huntsmen and of the drivers and trainers of animals. Animals are ruthlessly slain and dragged away from their young, that we may clothe our bodies in skins of wild beasts like pre-historic savages. They add their plumage to the abounding glory of women's hats; they are stripped of their skins to cover our feet and hands. We eat their bloody flesh. The huntsman wounds them and sends them maimed and bleeding to their lairs. Where one animal is mercifully destroyed for the sake of science, ten thousand are brutally slaughtered for man's vanity and sport. Male animals for food and draught, not preserved for breeding purposes, are subjected to a mutilating operation in numbers exceeding our power to grasp. These operations are practiced by the horny handed farmer, and we 162 
make no protest because he is raising tender meat for our stomachs. In the interest of science it has become necessary in England to organize a Research Defense Society. Research, in the country which produced Harvey, Hunter, Jenner, Darwin and Huxley, now needs defense! At the inaugural meeting of this society held in the building of the Royal Society of Medicine, Lord Cromer, the president of the society, delivered an eloquent address upon the value to mankind of animal experimentation, in which he stated that nearly every discovery in medical science since Harvey discovered the circulation of the blood was either directly or indirectly the result of experiments on animals. Professor Osler said that the discovery of the transmission of malaria by mosquitoes, the knowledge of which was destined to make the tropics habitable, never would have been made without animal experiments. The men who made these experiments had spent their lives in the research laboratories, and their whole work had been based upon such experiments.

Every scientific medical man is opposed to the efforts to restrict animal experimentation and study. There is not a medical society but 
favors animal research. With the exception of one or two men, who were notoriously erratic or in a decadent mental state, there has never been a member of the regular medical profession who could be called an eminent or even a prominent man who was opposed to animal experiments. The entire scientific medical profession is united in this important matter. Medical men, who are found in the ranks of "antivivisectionists," either are outside of the pale of scientific medicine and belong to some peculiar sect, or are examples of professional derelicts, habitual opponents, or covetors of notice. Happily there are but few of any of these. The opposition to research is outside of the biologic sciences.

When the question of vivisection was receiving legislative consideration in England, thirty-five years ago, Huxley declared that he trusted "to the fox-hunting instincts of the House of Commons rather than to any real interest in science in that body for a moderate treatment of the subject." In speaking his protest against the enactment of a law restricting animal experimentation in Massachusetts, President Eliot of Harvard, said: "The humanity which would prevent human suffering 164 
is a deeper and truer humanity than the humanity which would save pain or death to animals."

As an evidence of the unenlightened sentiment brought about in England by the opponents of science, that country now has a law which makes no objection to a boy trolling for fish or setting lines baited with live frogs but lays the teacher of the boy open to imprisonment and fine if he uses the same animal to demonstrate to the boy the circulation in the web of the foot without inflicting any pain and only subjecting the frog to the annoyance of being wrapped and restrained in a wet cloth. Now English scientists are going to France and Germany to carry on their studies. Some of the most important biologic discoveries which have been made by English scientists in recent years have been made on the continent. Lord Lister was compelled to go to France to complete his studies of antisepsis. This great benefactor said of the English law, "It serves no good purpose and interferes seriously with inquiries which are of paramount importance to mankind." Sir Michael Foster, the physiologist, wrote, "Men go out of England to do particular experiments. The necessity of a re- 
strictive law has never been shown." Sir Lauder Brunton said, "The passage of the antivivisection act in this country has interfered to an enormous extent with physiologic work. In order to make some of my investigations, the object of which was to find out the action of certain medicines, that one might apply them to the relief of suffering mankind, I have been obliged to go to Paris to carry on my research in a foreign laboratory."

Were $I$ to enumerate all of the pains inflicted on animals in the name of science, I would then say, these are but a drop in the ocean of pain which man visits upon the brutes; and were I to combine these two, and enumerate all of the pains both in the interest of science and humanity and in ruthless cruelty in sport and commerce which man visits upon animals, I would then say, these are but a drop in the ocean of pain which is visited upon the children of man in one single block in any great city. Let us give every aid to those who are endeavoring to mitigate some of this suffering.

Man's thirst for knowledge is his saving grace. It lifted him out of the world of mysticism and superstition in which he once lived. 
It will continue to lead him on and on to better things. It is ineradicably implanted in the human soul. Men have ever been willing to suffer and die for the sake of getting at the truth. When the dissection of human bodies was illegal, the hunger for knowledge could not be stopped. When animals are regarded as more precious than men, if animal experimentation should be prohibited, experiments would be made on men. Trying to combat diseases, the nature of which we do not understand, amounts to that. Shall we study disease upon animals, or upon men, women and children? When, as a result of accident or disease, one suffers destruction of parts or of organs, who is there who would prefer, to remedy the defect, to have an operation which had never been attempted before, when its practicability might have been determined upon a lower animal? We ourselves may be whole and sound of limb, but our hospitals are full of people to whom this is a pertinent question.

Ignorance has ever caused more pain than has the searching for useful knowledge. Let us by all means be kind to animals, chiefly because it teaches us to be kind to one another; 
but let us in our zeal for kindness to them not neglect that which is a still greater obligation -humanity to man.

Three hundred years ago, in Europe, the average length of human life was nineteen years. It has increased, with particular rapidity during the last half century, until now the average life of man is forty years. In Sweden, where the greatest governmental interest exists in the problems of public health, the average span of life has reached fifty-two years. Many diseases have been conquered; the mystery of many yet remains unsolved. The layman, in whose circle the visits of death are rare, may not grasp the meaning of these things. The physician, the biologist, and the sociologist know what they mean. The medical man, particularly he who works in the hospital, where daily he stands in the presence of those who are fatally ill, realizing his helplessness, turns to the workers who are striving to solve the problems of life and death, with a heart full of prayer for their success. To him the pale faces of the dying call for the help he can not give. The babe, the youth, the man in his prime, the loving mother-all of these he sees pass away because of the inadequacy of his 


\section{CONCLUSIONS}

art. Yet, some day, he feels, they shall be saved.

May the prayer be answered. May the day be soon. May those intellectual and humane forces, which so often have stayed the hand of death, steadfastly hold against the darkness the light of science. 


\section{INDEX}

Acromegaly, 102

Addison's disease, 102

Anderson, 66

Anesthetics in operations, 10

Antitoxins, 140

Antivaccinationists, 97

Antivivisection exhibit, 149

Antivivisectionists, 148

A n imal experimentation, meaning of, 5

Animals, diseases of, 132 study of, 9 transmission of disease by, 142

Aphasia, 51

Aristotle, 28, 105

Arterio-sclerosis, 113

Ashburn, 92

Asseli, 41

Assimilation, physiology of,41

Avicenna, 105

BACteria carriers, 66

Bancroft, 116

Barry, Richard, 160

Bashford, 118

Bayliss, 39, 155

Beaumont, William, 38

Behring, 78, 80, 127

Belialsky, 73
Bell, Sir Charles, 48

Berkley, 102

Bernard, Claude, 41, 103

"Bestiaries," The, 28

Billroth, 126

Black, Joseph, 36

Black-leg, 135

Black-water fever, 93

Blood, circulation of, 28

Blood vessels, surgery of, 122

Bollinger, 106

Bones, surgery of, 125

Borelli, 36

Bourgelat, 106

Boyle, Robert, 32, 35

Breger, 61

British Army, typhoid in, 62

Bruce, Major, 90

Brunton, Sir Lauder, 166

Busch, 103

Calvin, John, 31

Cancer, 116 of stomach, 129

Cannon, W. B., 39

Cardanus, 32

Carrel, Alexis, 124

Carroll, James, 82, 83, 84

Carter, 61

Castillani, 90 
Cats, carriers of disease, 142

Celsus, Cornelius, 105

Cerebro-spinal meningitis, 85

Cesalpinus, 52

Cholera, 75

Cohnheim, 117

Coleridge, antivivisectionist, 155,157

Conclusions, 145

Craig, 92

Cretinism, 100

Crile, George W., 33, 34

Criminal, condemned, 141

Crocker, Mr. George, 118

Cromer, Lord, 163

Cruelty to Animals, 22, 162

Czerny, 126

Dana, C. L., 158

Darwin, Charles, 3

Darwinism in medicine, 57

De Foe, $7 \mathbf{1}$

Deaderick, 93

Denis, Jean, 33

Dewey, John, 3

Diabetes, 103

Digestion, physiology of, 37

Diphtheria, 75

Diseases, infectious, 53 parasitic, 59

Dog, the, a menace, 143

Dogs, and babies, 160

as carriers of disease, 142

Drugs, experiments with, 119

DuHamel, 125

Dunn, 87

Dutton, 66, 90
Eberth, 60

Echinococcus, 142

Eliot, President, 164

Embryology, 46

Erasistratus, 27

Ethics of pain infliction, 24

Eugenies, 46

Eulenberg, 49

Experimental methods, 55

Fabricius, 28

Facies pathetica of animals, 18

Filarial disease, 115

Fitsch, 49

Flexner, Simon, 86, 88

Flourens, 48

Foot-and-mouth disease, 135

Forde, 90

Foster, Sir Michael, 165

Fraenkel, 61

Fuegians, tuberculosis among, 68

GALEN, 27, 29, 35, 47, 48, 105

Galvani, 52

Gaylord, H. R., 118

Germany, board of health of, 96

Giantism, 102

Glanders, 138

Glandular organs, 43

Glotz, 34

de Graaf, 40

Grassi, 92, 116

Gull, Sir William, 99 


\section{INDEX}

Haffkine, 74, 75

Hales, Stephen, 32, 52

Hall, Marshall, 49, 52

Hanan, 117

Harrison, 64

Harvey, William, 28, 30

Herophilus, 27

Herter, 39

Hertwig, 105, 106

Hirschfeld, 102

His, 117

Hitzig, 49

Hoffman, 37

Holt, L. E., 86

Hook-worm disease, 115

Horsley, Sir Victor, 48, 99, 100

Howell, 102

Hughes, 61

Hunter, John, 41, 122, 125, 126

Huxley, Thomas, 112

on the House of Commons, 164

Hydrophobia, 104

INDiA cattle-fever, 92

Infectious diseases, 53

Influenza, antitoxin for, 139

Infusion and transfusion, 32

Insects as carriers, 92

Internal secretions, 42

Intestinal surgery, 124

J ACKson, 49

James, S. P., 116
Janet, 158

Jenner, Edward, 94

Jensen, 117

Kitasato, 71, 78, 127

Klebs, 75, 78, 79, 80

Klemperer, 61

Klencke, 67

Knowledge, biologic, evolution of, 2

Koch, Robert, 67, 75, 90, 143

Kocher, Theodor, 43, 123

Kronecker, 34

LANDOIS, 49

Landsteiner, 87

Lavoisier, 36, 37

Laws, Bad, 133, 136, 165

Lazear, Jesse W., 82, 83, 84

Lebert, 117

Leeuwenhoeck, 29

Leonard, 103

Lewis, P. A., 88

Life, a contest, 59

Lind-ap-Hageby, Miss, 157

Lister, Lord, 111, 123, 165

Loeb, 117

Loeffler, 75, 78, 79, 80

Low, G. C., 116

Lowes, 32

Luciani, 48

Magnus, 37

Malaria, 84 and consumption, 85

Malpigi, 29

Malta fever, 93 
Manchot, 61

Matas, 123

Mayo, 35

Medicine and hygiene, 53

Meltzer, 39

Mering, 40, 103

Meson, 115

Metchnikoff, 113

Meynell, 105

Minkowski, 40, 103

Mitchell, S. W., 113

Moore, V., 108, 110

Morean, 117

Morel, 158

Motor area, 50

Munk, 50

Myxedema, 99

Negri, 107

Nervous system, physiology of, 47

surgery of, 121

Nicollaier, 127

von Niemeyer, Felix, 109

Nobel prize, 44

Noe, 116

Ollier, 125

Operations, exploratory, 129 painlessness of, 20

Orphans in United States, 159

Osborne, 102

Osler, W., 163

Ott, 34

Oxygen, physiology of, 36

Pain, a human attribute, 15 a special sense, 16
Pain, animals have little, 17 interpretation of, 18 meaning of, 15 unnecessary, 22

Painlessness of experiments, 13

Parasitic diseases, 59

Pasteur, Louis, 107, 109, 111, 112, 143

life of, 112

Pawlow, 39

Pfeiffer, 61

"Physiologus", the, 28

Physiology and experimentation, 26 early Christian, 27 primitive, 26 technic in, 10

Pituitary body, 45

Plague, 71

Pleuro-pneumonia, 135

Poliomyelitis, 87

Popper, 87

Potter, 32

Priestly, Joseph, 35

Psychosis, zoöphilic, 158

RABIES, 104

Rabinowitch, 143

Radi, 106

Rayer, 138

Raymond, 158

Reed, Walter, 82, 83, 84

Reflex movements, 19

Regeneration, 45

Relapsing fever, 99

Remak, 117 


\section{INDEX}

Reschtnikoff, 73

Research Defense Society, 163

Respiration, physiology of, 35

Rhazes, 105

Ricketts, 93

Rights of man over animals, 23

Rinder-pest, 139

Rockefeller, J. D., 115

Rockefeller Institute, 86, 88, 156

Rocky Mountain fever, 93 Ross, 92

Roux, 78, 107

Royal Commission of Vaccination, 95

SANDER, 34

Schaefer, 50

Schiff, 43, 44, 99

Scorpion sting, 114

Secretions, internal, 42

Servetus, Michael, 31

Shafer, 102

Sherrington, 50

Simpson, Sir James Y., 120

Sleeping sickness, 89

Small-pox, 93

Snake bite, 113

Spallanzani, 37

Speech center, 50

Spontaneous generation, 27

Starling, Professor, 13, 39

St. Martin, Alexis, 38

Suprarenal capsules, 44
Surgery and experimentation, 121

Sym, 125

Syphilis, 88

Swenzy, Sir H. R., 126

TAPe Worm, 142

Teaching purposes, 12

Technic of experimentation, 9

Tetanus, 126

Texas fever, 133

Thamhayn, 106

Thyroid secretion, 43

Todd, Charles, 120

Toynbee, 120

Transfusion and infusion, 32

Transplantation of organs, 123

Trichinæ, 132

Trudeau, 68

Trypanosoma, 90, 92

Tsetse fly, 90, 92

'Tuberculosis, 66

in animals, 136

in birds, 143

in Germany, 70

Typhoid fever, 60

in the United States, 65

spread by flies, 65

Vaccination, 94

against typhoid, 61

Vallee, 136

Vesalius, Andreas, 2, 28

Villemin, 67 


\section{INDEX}

Virchow, 117

Vivisection, errors concerning, 7

Vogel, 37

Waldeyer, 117

Whyatt, Robert, 52
Wright, Sir Almroth E., 63, 103

YAws, 93

Yellow fever, 82

Yeo, Gerald, 14

Youatt, 105

ZoOphylic PSYChOSIS, 158 
, 


,



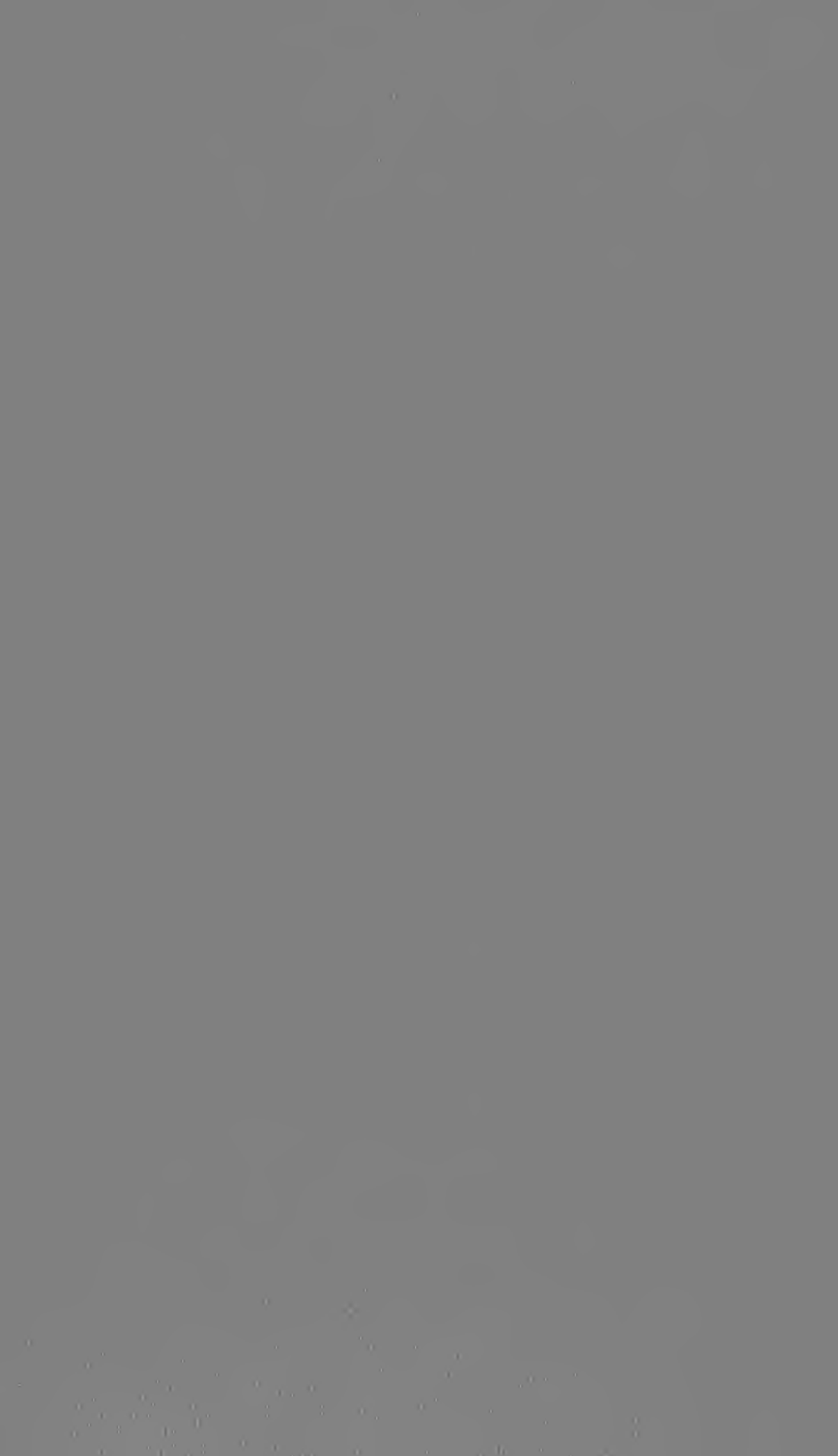